\title{
Bio-inspired polymer-polymer hybrids for medical applications
}

\author{
Gökhan Demirci, Malwina Niedźwiedź, Nina Kantor-Malujdy, Miroslawa El Fray* \\ Department of Polymer and Biomaterials Science, \\ Faculty of Chemical Technology and Engineering, \\ West Pomeranian University of Technology in Szczecin \\ Al. Piastow 45, 70-311 Szczecin, POLAND
}

\begin{abstract}
Novel bio-inspired materials have gained recently great attention, especially in medical applications. Applying sophisticated design and engineering methods, various polymer-polymer hybrid systems with outstanding performance have been developed in last decades. Hybrid systems composed of bioelastomers and hydrogels are very attractive due to their high biocompatibility and elastic nature for advanced biomaterials used in various medical applications such as drug delivery systems and scaffolds for tissue engineering. Herein, we describe the advances in current state-of-the-art design, properties and applications of polymer-polymer hybrid systems in medical applications. Bio-inspired functionalities, including bioadhesiveness, injectability, antibacterial properties and degradability applicable to advanced drug delivery systems and medical devices will be discussed in a context of future efforts towards development of bioinspired materials.
\end{abstract}

\section{Statement of Significance}

Bio-inspired materials have become a powerful tool to enhance the applicability of hybrid systems, e.g. inorganic/organic and hydrophobic/hydrophilic in medical field. However, in-depth analysis on recent developments on polymer-polymer hybrid systems has not been comprehensively reported. Herein, the polymer-polymer hybrid systems are summarized by their origins, key futures and selected medical applications such as drug delivery systems and scaffolds for tissue engineering. In this review, while showing the syntheses of the hybrid systems by their natural or synthetic origins, the most recent (since 2015) studies are given for the key features indicating their importance in medical science for further progresses and developments in material science.

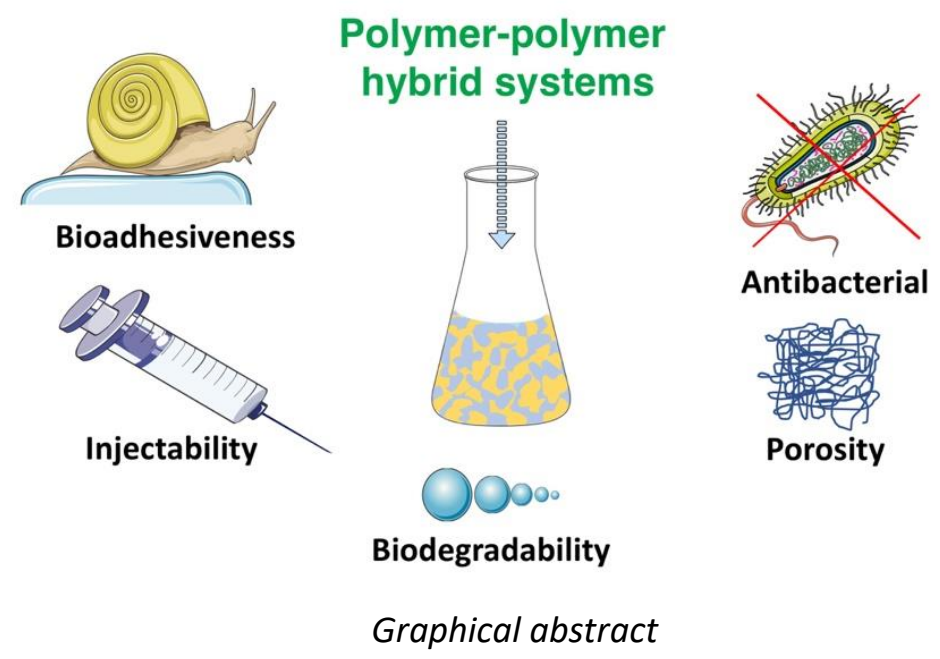

Key words: bio-inspired structures, bioelastomers, hydrogels, polymer-polymer hybrids, injectable biomaterials, adhesive surfaces

*Corresponding author: mirfray@zut.edu.pl 


\section{Introduction}

The structure of biological materials has been fine-tuned over millions years of evolution. The study of live organisms to derive new principles and technologies, and then applying them to manmade materials, including polymers and composites to emulate biological functions and performance is in a central place of biomimetics (bioinspiration). Following the principles of designing materials with defined biological properties, such as bioactivity, adhesiveness, self-healing, etc., the use of polymeric materials in medicine is one of the most important application areas in restoring health, interacting therapeutically or ultimately replacing diseased tissues or organs. The diversity of chemical structures, synthesis possibilities and origin/sources make polymers important in controlled release of drugs, implants for tissue reconstruction, medical devices and many other [1][2][3][4][5]. Naturally-occurring polymers were the first to be used in medical applications around the 1960s. The most common representatives of natural polymers are proteins, polysaccharides and polynucleotides [6]. The main advantage of those natural polymers is high biocompatibility due to their chemical structure. Nevertheless, these polymers can cause an immune response due to the possible impurities occurring from processing. Natural materials fabrication typically involves decellularization and removal of antigenicity, to obtain material that will not cause an immune response after implantation. Therefore, synthetic materials which are obtained via precision macromolecular engineering or well established polymerization processes have often better properties, both physical and biological, thus being frequently developed and used in medical applications. They can be engineered towards very complex supports for tissues and organs that exhibit organized heterogeneity within multiple cell types [7].

Historically, synthetic materials were designed as structural components of medical devices with tailored stability/degradation time. However, rapid development of materials engineering has triggered the new trend to incorporate the natural polymers sophistication into synthetic polymer structures, to introduce biological cues that are necessary to support or replace the targeted tissue or organ and to better understand how these features can be created more effectively [8]. Advances in manufacturing strategies have ensured additional contributions to biomaterial design [9]. Thus, hybrid systems, often inspired by nature, containing natural and synthetic structural elements/polymers of distinct but often complementary or synergistic properties, are rapidly being developed to better optimize final performance of medical devices.

This review is focused on the bio-inspired hybrid polymer-polymer systems derived from distinctly different polymeric materials (natural origin and synthetic, hydrophobic and hydrophilic, stiff and elastic) to create functionalities resembling biological tissue properties. Recent advances in development of bioelastomers and hydrogels as naturally present components of biological tissue will be reviewed from the perspective of their functionality as hybrid systems with tailor-made bioadhesiveness, injectability, porosity, biodegradation and elasticity.

\section{Polymer-polymer hybrid materials}

Polymer-polymer hybrid materials have gained a great attention due to combination of various structural characterizations and diverse functionalities. The combination of two or more polymer materials, commonly of natural and synthetic origin in polymer-polymer hybrid systems, is offering a remarkable properties and multifunctionalities through the combination of different structural components (Figure 1). Hybrid polymer-polymer systems, in contrary to interpenetrating polymer networks (IPN) which are not covalently bonded to each other, can be created by covalent bonds or non-covalent interactions such as hydrogen bonding, van der Waals and electrostatic interactions. Differences in preparation methods lead to changes in properties of the hybrid materials thus improving their applicability in different areas. Hybrid systems have been widely used in various applications, including paintings [10][11], construction industry [12], dentistry [13], medicine [14][15] and nanoscience [16][17]. 


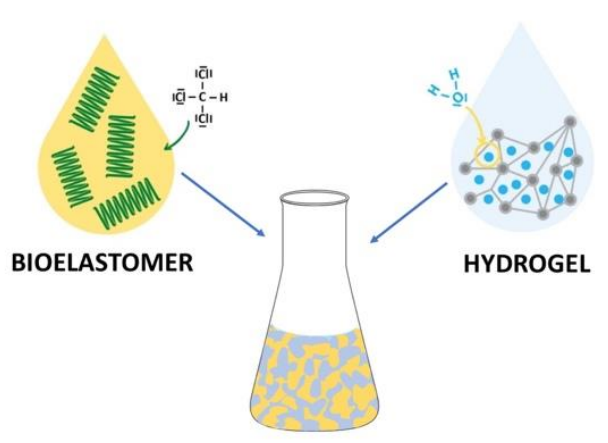

Polymer-polymer hybrid system

Figure 1. Schematic representation of polymer-polymer hybrid systems

In last decades, polymer-polymer hybrid systems triggered more attention in the medical applications due to their specific physico-chemical key properties such as enhanced mildness, solubilization, density, permeability, stiffness, low surface tension, stability, mesh size and structure. Moreover, their biocompatibility, biodegradability, non-immune response and structural similarity to extracellular matrix (ECM) have attracted the researchers to focus on new developments in medicine [17]. Properties of polymer-polymer hybrid materials can be structured through selection of their chemical composition, density, cross-linking strategy, structure stabilization, hydrophobicity/hydrophilicity ratio, etc.

Among various groups of polymers, bioelastomers have been developed for medical applications. Both thermoplastic elastomers such as polyurethanes [18], poly ( $\varepsilon$-caprolactone) copolyesters [19], poly(ether ester)s [20] and thermoset elastomers such as crosslinked polyesters [21] have been developed for heart valves and muscles applications, skin, cartilage implants, blood vessels, vascular catheter and wound dressings. Simultaneously, hydrogels show physico-chemical similarity with ECM and provide high-water content are considered as highly biocompatible materials. Therefore, in last decades, the use of soft elastomers and hydrogels is increasing rapidly in medical applications [22][23][24][25][26]. Rational design of bioelastomers and hydrogels could be a solution to obtain welldesigned hybrid materials with tailor-made elasticity and wettability while preserving or creating strong adhesion between the components or with the biological tissues.

Such components of hybrid systems can be attached to each other either by physical and/or chemical interactions creating interlinks (strong bonds) or topological entanglements. An excellent example is a silane coupling agent (SCA) introduced into the precursors of a cured polydimethylsiloxane (PDMS) elastomer and polyacrylamide (PAAm) hydrogels. After manufacturing, SCA condensates and creates bonds across the interface and improve adhesion independently from the sequence of forming the networks. In another study, various addition sequences on bonding energy were investigated such as cured hydrogel and cured bioelastomer, cured hydrogel and uncured bioelastomer, uncured hydrogel and cured bioelastomer (Figure 2) [27]. 


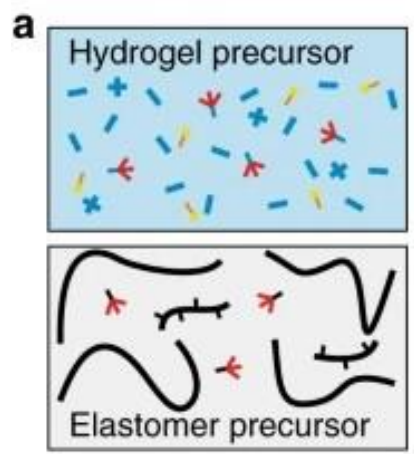

ネ Coupling agents

I Surfactants

d<smiles>[X][Si]([R])([O-])O[Na]</smiles>

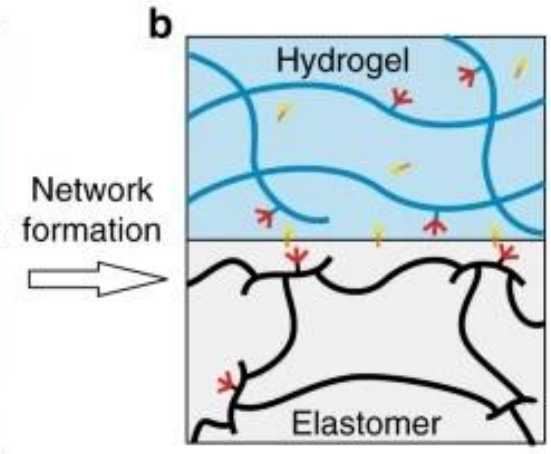

- + Monomer/crosslinker in hydrogel

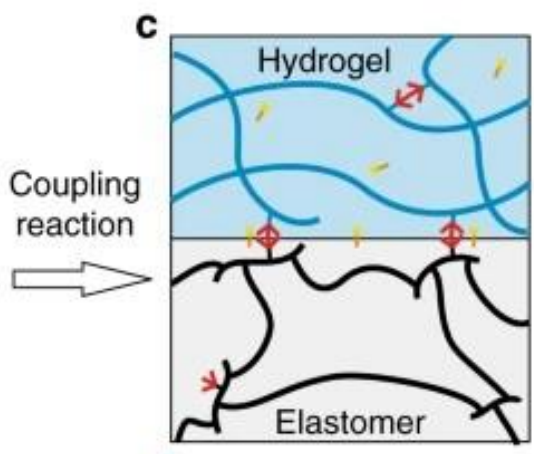

tr Hydrogel network

工c Elastomer network

f

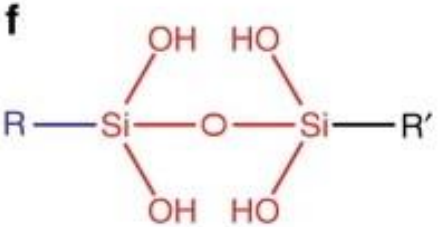

Figure 2. A hydrogel and an elastomer forming covalent bonds after a manufacturing process. Reproduced from [27] with permission. Copyright (C 2018 Qihan Liu et al.

\section{Components of polymer-polymer hybrid networks}

Polymer networks, which are all polymer chains connected with each other either covalent or noncovalent interactions. Creation of polymer networks involves polymerization and crosslinking, with a very broad component selection for the targeted application. Components of polymer-polymer hybrid systems can be extremely diverse and derived either from natural or synthetic sources (Figure 3). In this review we will focus on bioelastomers and hydrogels as very interesting and diverse components of polymer-polymer hybrid networks.

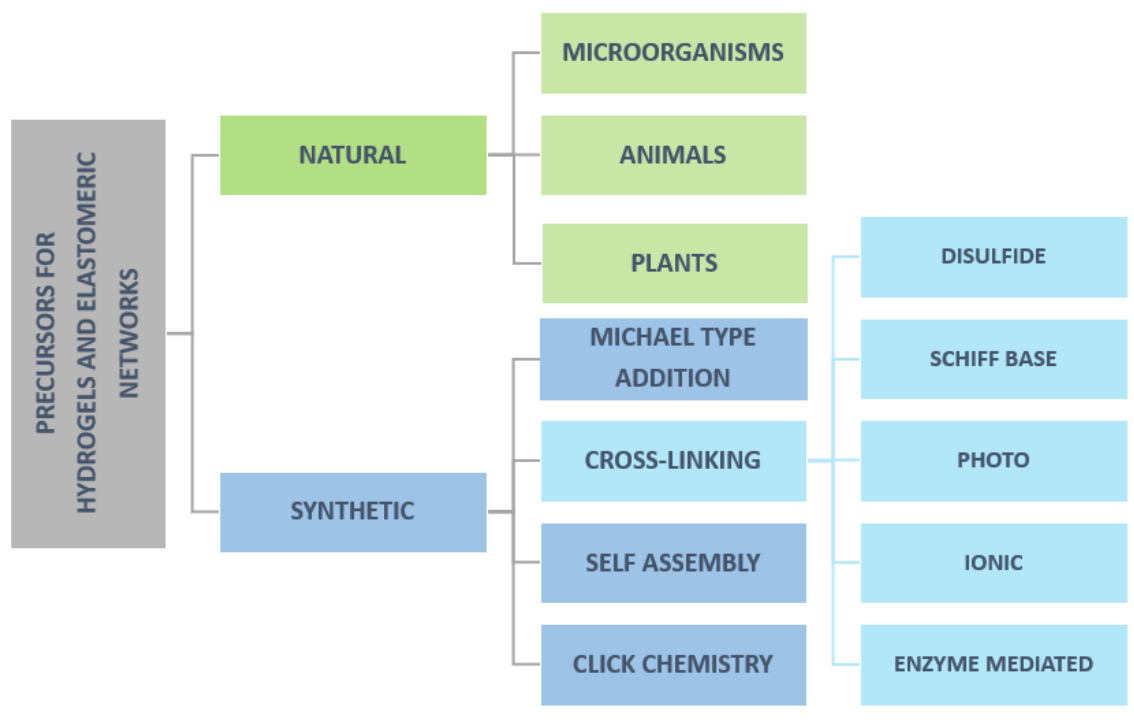

Figure 3. Natural and synthetic precursors of hydrogels and elastomeric networks as main components of polymer-polymer hybrid systems 


\subsection{Bioelastomers}

Elastomers are a class of polymeric materials that can repeatedly and easily undergo large, reversible deformations with complete recovery [28]. They are usually composed of long-chain molecules, extremely flexible due to their ability to reconfiguration themselves to dissipate an applied force. The main feature of elastomers is viscoelasticity, thus making them suitable for different medical applications such as drug delivery systems [29][30], biosensors [31][32], artificial organs [33][34], regenerative medicine [35][36], and tissue engineering [18][37][38].

Specifically, bioelastomers, also called "biomedical elastomers", have been engineered to be used in human or veterinary medicine [39]. They are suitable for medical applications due to their great attributes such as 3D-crosslinked network structure, good mechanical properties and possibility of tailoring degradation by introducing functional groups within the structure [38].

The versatility of bioelastomers originates from a wide design window, where natural (biopolymers) and synthetic bioelastomers can be used to gain the required properties for targeted applications.

\subsubsection{Natural bioelastomers}

Natural bioelastomers are characterized by their inherent biocompatibility, biodegradation, hydrophilic character and high bioactivity, which is promising for regenerative medicine. Mainly, natural-origin bioelastomers are proteins, including collagen, elastin, fibrin, chitin [40] and resilin [41][42]. Mechanical properties of the most popular ones (collagen, elastin and fibrin) are shown in Table 1.

Table 1. Mechanical properties of proteins

\begin{tabular}{|c|c|c|c|c|c|c|}
\hline Proteins & $\begin{array}{c}\text { Dominant } \\
\text { amino acids }\end{array}$ & Distribution & $\begin{array}{c}\text { Young } \\
\text { modulus } \\
{[\mathrm{MPa}]}\end{array}$ & $\begin{array}{c}\text { Tensile } \\
\text { strength } \\
{[\mathrm{MPa}]}\end{array}$ & $\begin{array}{c}\text { Elongation } \\
{[\%]}\end{array}$ & References \\
\hline Collagen & $\begin{array}{c}35 \% \text { Glycine, } \\
12 \% \text { Proline }\end{array}$ & $\begin{array}{c}\text { Bone, teeth, } \\
\text { vasculature, } \\
\text { organs }\end{array}$ & $100-2900$ & $5-500$ & $5-50$ & {$[43]$} \\
\hline Elastin & $\begin{array}{c}32 \% \text { Glycine, } \\
21 \% \text { Alanine }\end{array}$ & $\begin{array}{c}\text { Skin, lungs, } \\
\text { vasculature }\end{array}$ & $0.3-0.6$ & $0.36-4.4$ & $100-220$ & {$[44]$} \\
\hline Fibrin & $\begin{array}{c}45 \% \text { Glycine, } \\
30 \% \text { Alanine }\end{array}$ & Blood & $1.7-14.5$ & $0.01-0.02$ & 100 & {$[45][46]$} \\
\hline
\end{tabular}

The most popular bioelastomer is collagen, a type of fibrous proteins, which is the main structural component of connective and bone tissue. Collagen structure is mostly dominated by rigid secondary regions of triple-helix, thus resulting in 29 types of collagen. Collagen is flexible macromolecule, with strain at break of $10-20 \%$ and a resilience of $90 \%$ [41]. Elasticity of collagen may differ depending from the structural arrangement of fibrous tracts. For instance, bone collagen has higher density of intermolecular crosslinks than soft tissue collagen. Another important bioelastomer, elastin, mostly contain amorphous, random-coil domains which result in high elasticity of this protein, thus directly contributing to organs' elasticity [35]. Interestingly, it has rubber-like properties that means providing high elasticity, extensibility and resilience. Elastin can be formed an insoluble network as a result of hydroxylation and crosslinking. Elastin is widely used in soft tissue engineering e.g. split-skin autografts for burn wounds, gastrointestinal patches, heart valve replacement and vascular grafts [41]. However, natural elastin is not used often in cardiovascular prosthetic implants due to its purification, batch-tobatch variations, and high propensity to calcification due to its poorly defined purification [47]. Exceptional properties of another biomacromolecule, fibrin is directly connected with blood clotting process assisting wound healing. Therefore, this bioelastomer is used in materials for skin grafts. Fibrin 
shows mitogenic, chemotactic and proangiogenic activities and even degradation (coagulation and fibrinolysis) products are an activators of wound repair [48]. This protein is widely used in many applications due to rich bioactivity and easily manipulation. Fibrin can be a perfect candidate for the cell instructive scaffolds due to three-dimensional organization and injectability which minimizes the invasiveness of the procedure and biodegradation within short period of time (1-26 weeks) [36][49].

\subsubsection{Synthetic bioelastomers}

In order to mimic elastomeric and biological properties of natural origin bioelastomers, the synthetic materials are being rapidly developing in last decades. The most popular synthetic bioelastomers belong to the group of polyesters where mechanical properties (elasticity) and degradation in various environments can be tailored by applying various monomers and synthesis routs, preferably in bulk, without solvents [50]. Synthetic bioelastomers are usually linear polymers or block copolymers formed by polyaddition, ring-opening polymerization and polyaddition of difunctional or cyclic monomers [51][52][53][54][55]. Bioelastomer structure can be stabilized by chemical or physical crosslinking (Figure 4). Chemically crosslinked elastomer chains and/or segments are interconnected into a three-dimensional network structure by covalent bonds, which are introduced during the curing process. Curing can be performed by radiation or thermal processes. The most popular elastomers in this group are poly(ethylene glycol) (PEG), poly( glycerol sebacate) (PGS), poly(glycerol sebacate-co-acrylate) (PGSA). In physically crosslinked bioelastomers, elastomeric chains/segments are associated by weak hydrogen bonds, van der Waals forces, dipolar forces, microcrystalline or glassy domains [56]. Main groups of physically crosslinked materials are polyurethanes (PUs), polyesters, copolyesters and styrene-based elastomers [53].

a)

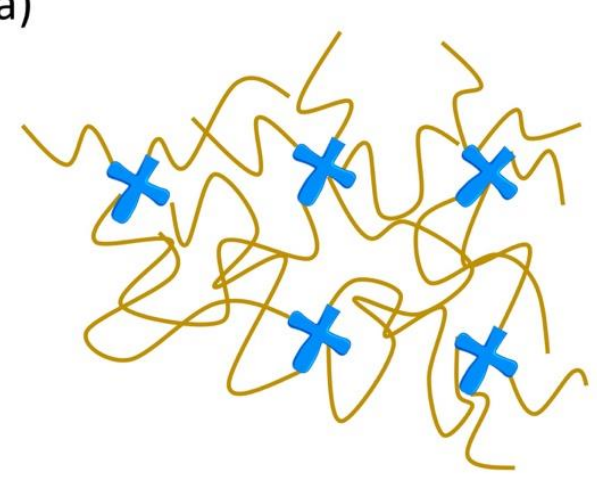

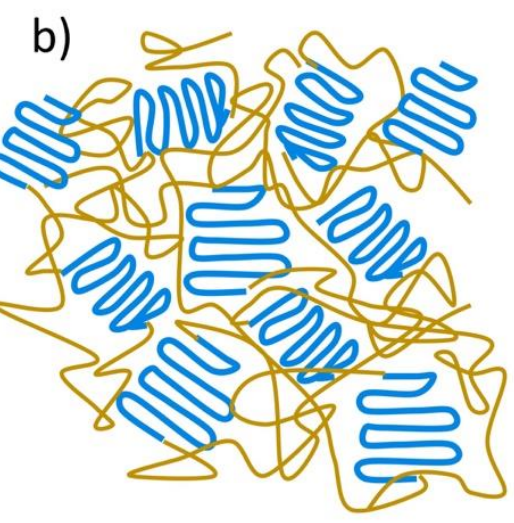

Figure 4. Schematic structure of chemically crosslinked (a) and physically crosslinked (b) elastomers

Thermoplastic polyesters and their copolymers currently have dominated the field of biomedical materials. Most of them are highly biodegradable and hydrolysable to metabolic products. The most popular ones are poly(lactic acid) (PLA), poly(glycolic acid) (PGA), poly(e-caprolactone) (PCL) and, their copolymers and blends. Polyesters can result in direct reaction between carboxylic acid (-COOH) and hydroxyl group $(-\mathrm{OH})$ usually from alcohol. However, the synthesis route can include single or double ester exchange, acidolysis, activated condensation or carboxylate polymerization reaction with the use of acid halides [57].

An interesting example of condensation copolyesters are segmented block or random copolymers containing alcohols or acids derived from long chain fatty acids which are endogenous to human body [58]. Many studies have proven that polyesters containing either terephthalic acid (PET) or poly(butylene succinate)(PBS) are biocompatible and exhibit good mechanical properties for soft tissue engineering applications [59][60]. Characteristic feature of thermoplastic elastomers is heterogeneous 
degradation as a result of which loss of mechanical properties occurs. In heterogeneous degradation, the crystalline domains are more resistant to degradation than amorphous regions [61].

Another recently developed bioelastomers are poly(diol citrates) (PCC) synthesized through polycondensation of citric acid (CA) and various diols which have significant influence on properties of the final materials. CA is one of the products of human metabolism, created during Krebs and citric cycle. Another advantage is low price and availability of citric acid. According to Yajing Zhou el al., molar ratio of monomers and thermosetting conditions also have crucial effects on the properties of the PCC as demonstrated by elongation ranging from $70 \%$ to $260 \%$ [62][63].

Polycondensation of glycerol and sebacic acid has resulted in poly(glycerol sebacate)(PGS), highly elastomeric polymer mimicking collagen and elastin found in extracellular matrix [64]. The inherent components of this polymer are natural metabolic compounds, where glycerol is involved in the synthesis of phospholipids and sebacic acid is important for synthesis of fatty acid. Poly(glycerol sebacate) has been found to be biodegradable at low crosslink density [65]. PGS, as many condensation polymers, where properties can be simply tailored by weigh content of monomers on the feed, is capable to form variety of polyester networks from low molecular weight multifunctional alcohols and carboxylic acids. PGS has extraordinary potential in soft and hard tissue engineering [65][66][67][68].

Dopant-free conductive polyurethane elastomer (DCPU) was made up of poly (caprolactone) (PCL) (biodegradable segment), aniline trimer with two amine end groups (conductive segment), and dimethylolpropionic acid (DMPA) (dopant molecule) with 1,6-hexamethylene diisocyanate (HDI). According to Cancan Xu et al., DCPUs is biodegradable, degradation can occur through hydrolysis and oxidation by enzymes. Furthermore, DCPU films and product of their degradation during cytotoxicity test with 3T3 fibroblast showed good cell viability. Mechanical properties demonstrate high elasticity the breaking strain ranging from $685 \%$ to $825 \%$ and indicating potential of this material in medical applications [32]. Mechanical properties of synthetic bioelastomers are summarized in Table 2.

Table 2. Mechanical properties of synthetic bioelastomers

\begin{tabular}{|c|l|l|l|l|c|}
\hline $\begin{array}{c}\text { Name of } \\
\text { material }\end{array}$ & $\begin{array}{c}\text { Crosslinking } \\
\text { type }\end{array}$ & $\begin{array}{c}\text { Young } \\
\text { modulus } \\
{[\mathrm{MPa}]}\end{array}$ & $\begin{array}{c}\text { Tensile } \\
\text { strength } \\
{[\mathrm{MPa}]}\end{array}$ & $\begin{array}{c}\text { Elongation } \\
{[\%]}\end{array}$ & References \\
\hline PCC & chemical & $140-1737^{*}$ & $171-977^{*}$ & $70-260$ & {$[61]$} \\
\hline PGS & chemical & $0.056-1.5$ & 0.5 & $40-450$ & {$[37]$} \\
\hline DCPU & chemical & $0.5-3.8$ & $9.6-20.3$ & $170-190$ & {$[32]$} \\
\hline PGSA & chemical & $0.05-1.38$ & $0.05-0.5$ & $42-189$ & {$[63]$} \\
\hline PCL & physical & $210-340$ & $10.0-60.0$ & $300-1200$ & {$[39][69][70][71][72]$} \\
\hline PBS & physical & 550 & $20.0-40.7$ & $100-224$ & {$[72][73][74]$} \\
\hline PGA & physical & 6900 & 68.9 & $15-20$ & {$[37][69]$} \\
\hline
\end{tabular}

*depends on conditions especially temperature

\subsection{Hydrogels}

Hydrogels (HGs) are macromolecular structures consisting of polymer networks with the ability to absorb water without dissolving. Water is held between the polymer chains, which gives material elastic features, however, hydrogels become a rigid macromolecular tangled structure when the water evaporates. The features of HGs such as their hydrophilic character, a similar structure to tissues, ability to degrade, chemical stability and the possibility to absorb an immense amount of water or biological fluids, $\mathrm{HGs}$ are eligible for tissue engineering and regenerative medicine (TERM).

The journey of HGs usage in medical applications has started with Professor Otto Wichterle in 1960 by developing poly(2-hydroxyethyl methacrylate) (PHEMA) for eye lenses [75]. Then Cornhill et al. proved that HGs provide an excellent protective barrier, and they filled the wound while being stable 
at body temperature and enable water vapor permeability [76]. Owing to those two examples, hydrogels came into daily use and began to increase more attention, especially, in drug delivery systems. Kim et al. was able to introduce a drug (liquiritigenin) into the body by hydrogels via skin due to the loosening skin barrier through skin hydration [77][78].

Most hydrogels consists of natural and synthetic moieties. An important aspect is designing such a material to properly combine the expected features of various components for subsequent applications. Figure 5 shows the possible hydrogel structure with its components for drug delivery system. The parameters that are significant for hydrogels to be used as matrices are the degradability, mechanical strength and form of the drug delivery.

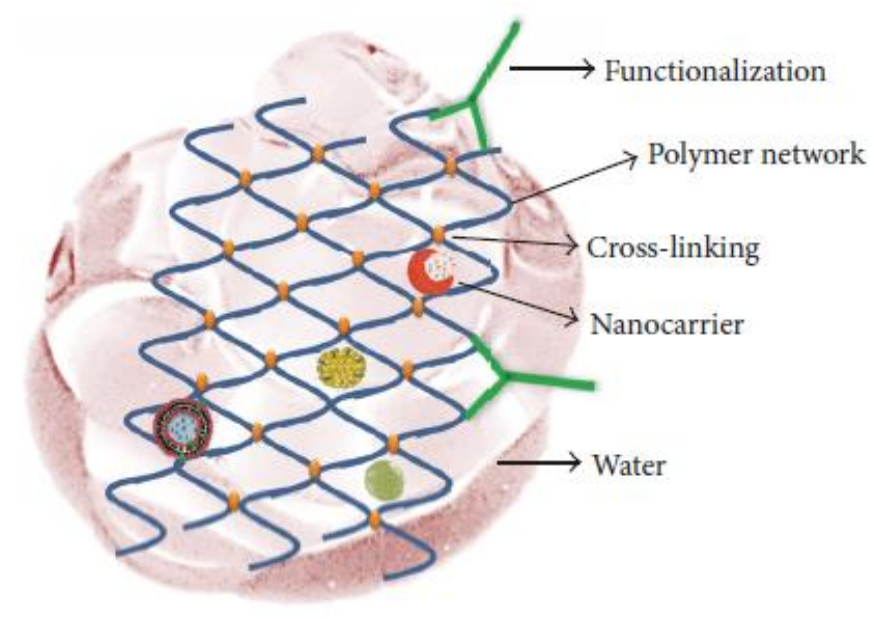

Figure 5. Demonstration of possible hydrogel structure for drug delivery system. Reproduced from [159] with permission. Copyright (c) 2017 Lígia N. M. Ribeiro et al.

Attention should be paid to chemical modifications or filling HGs with components such as drugs or cells, which may be an obstacle in combining an already processed matrix. The form of HGs to be placed in the body is usually challenging, so nowadays, the design of injectable materials gained popularity. As a positive feature, the environment of hydrated structure of HG protects drugs and cells, and ensures good transport of nutrients to the cells [21]. Another important aspect is that all components of HGs (monomer, initiator and crosslinker) are entirely reacted during the formation process, or the side products are efficiently removed since unreacted products can significantly deteriorate chemical and physical properties. Therefore, relatively low toxic and high effective components are used [79].

HGs can be divided by their sources into natural, synthetic and semi-synthetic origins. The advantage of natural components is their non-toxicity, biocompatibility, and degradation. However, they are often unstable. On the other hand, synthetic HGs ensure stability but are hard to degrade. Therefore, by combination of natural and synthetic components, the final properties can easily be tuned for medical applications [80][81][82].

\subsubsection{Natural hydrogels}

Hydrogels occurring in nature can be divided into two main groups: polysaccharides such as chitosan, hyaluronan, alginate, agarose, and proteins. Natural HGs promote good cell interactions and adhesion thanks to their origin. As natural materials they also marked by biodegradability, biocompatibility and low cytotoxicity. Based on polysaccharides that connect using the Schiff-type reactions aldehyde hydroxyethyl starch (AHES) and amino carboxymethyl chitosan (ACC), the rapidly forming in situ hydrogel has a homeostatic ability, which is a particularly attractive property for tissue adhesives [83]. Natural hydrogels are mainly used for articular cartilage tissue engineering due to similar consist of water which is from $60 \%$ to $90 \%$ for hydrogel and about $70 \%$ in ECM of cartilage tissue. Stimuli-responsive polysaccharide hydrogels are intelligent hydrogels that change form in 
response to factors such as $\mathrm{pH}$, light, pressure etc. Polysaccharide HGs exhibit storage properties to immobilize molecules, which makes them interesting for biomedical usage [84].

\subsubsection{Synthetic and semi-synthetic hydrogels}

Synthetic hydrogels can be generated chemically which is called chemical HGs by crosslinking polymers with radiation, click chemistry reactions [85][86], or Michael type addition [87]. Physical HGs can be formed by warming or cooling the polymer solution, mixing polyanion and polycation solutions, or lowering $\mathrm{pH}$ to attach via hydrogen bonds polymers in an aqueous solution [79][88][89]. Both chemical and physical HGs are inhomogeneous due to their interior structure. They consist of areas entitled 'clusters' that swell a low amount of water because of high crosslinking density. In opposite, there are also low crosslinked density regions or even full of water spaces or macropores. Synthetic HGs offer an advantage over natural HGs that they are more controllable however less biologically active. The composition or architecture of the matrix need to be considered. Features of synthetic and semi-synthetic hydrogels such as biocompatibility, reproducibility, mechanical properties and biodegradability are crucial. Therefore, attention goes towards selection of HGs components for specific applications.

Designing a synthetic hydrogel in the application of being a carrier of cells, one should consider the balance that needs to be kept between the biodegradation time and mechanical properties of HGs and ECM, and the growth of the desired tissue. Polymeric particles (macromolecules and proteins), similar to natural ones, influence the structure of tissues, and behavior of cells, which contributes to the regulation of cell functions. Some of the biodegradable synthetic $\mathrm{HGs}$ are poly( $\mathrm{N}$-isopropylacrylamide) (PNIPAAm), poly(ethylene oxide)-poly(propylene oxide)-poly(ethylene oxide) (PEO-PPO-PEO), triblock copolymer consisting of poly (lactic acid-co-glycolic acid) (PLGA) and poly(ethylene glycol) (PEG) (PLGAPEG-PLGA) or poly(ethylene glycol)-polylactide-poly(ethylene glycol) (PEG-PLA-PEG). PEG derivatives which are mostly combined with fibrinogen, hyaluronic acid or poly (propylene fumarate) are used in particular adhesives and scaffolds [88][90]. Zant and Grijpma synthesized and crosslinked macromers based on poly(trimethylene carbonate)(PTMC), poly(D,L-lactide)(PLL), poly( $\varepsilon$-caprolactone)(PCL) and PEG by using photopolymerization, and the obtained synthetic HGs showed high water uptake, remarkable ability to promote cell adhesion and proliferation [91]. As another example, modified alginates with 2-aminoethyl methacrylate (AEMA) subjected to photo-crosslinking are excellent materials for creating a filler or a scaffold because of slow degradation. Gelation occurs in vivo, and mechanical properties were improved, supporting the components of cartilage tissue [81]. Mechanical properties of commonly used hydrogels are given in Table 3.

Table 3. Mechanical properties of commonly used hydrogels

\begin{tabular}{|c|c|c|c|c|c|}
\hline Synthetic HGs & $\begin{array}{c}\text { Crosslinking } \\
\text { type }\end{array}$ & $\begin{array}{c}\text { Young } \\
\text { modulus } \\
{[\mathrm{MPa}]}\end{array}$ & $\begin{array}{c}\text { Tensile } \\
\text { strength } \\
{[\mathrm{MPa}]}\end{array}$ & $\begin{array}{c}\text { Elongation } \\
{[\%]}\end{array}$ & References \\
\hline $\begin{array}{c}\text { Poly(ethylene glycol) } \\
\text { (PEG)/polydimethylsiloxane } \\
\text { (PDMS) hydrogel }\end{array}$ & chemical & $0.006-0,36$ & $0.02-0.42$ & 30 & {$[88]$} \\
\hline $\begin{array}{c}\text { Chitosan (CS) and poly(vinyl } \\
\text { alcohol) (PVA) (CS/PVA) }\end{array}$ & chemical & $2.3-2.5$ & $6.0-9.70$ & $16.3-28.1$ & {$[92]$} \\
\hline $\begin{array}{c}\text { Tunicate cellulose } \\
\text { nanocrystals (TCNCS) aligned } \\
\text { (anisotropic d-Gel) }\end{array}$ & physical & 152.1 & $13.7-56.2$ & 1400 & {$[93]$} \\
\hline $\begin{array}{c}\text { Aluminum ion cross-linked } \\
\text { hydrogel (Gel) high- } \\
\text { modulus hydrogels (HM-Gel) }\end{array}$ & physical & $0.59-1.94$ & $1.26-1.74$ & $550-650$ & {$[94]$} \\
\hline
\end{tabular}




\begin{tabular}{|c|c|c|c|c|c|}
\hline $\begin{array}{c}\text { Carboxymethyl } \\
\text { cellulose/polyacrylic acid } \\
\text { hydrogel (CMC/PAA) }\end{array}$ & physical & $0.065-0.18$ & $0.40-0.85$ & $350-700$ & [95] \\
\hline $\begin{array}{c}\text { PDLLA-dMA-PCL-dMA-PEG- } \\
\text { dMA hydrogel }\end{array}$ & physical & $1.4 \pm 0.2$ & $0.47 \pm 0.06$ & $84 \pm 22$ & {$[96]$} \\
\hline $\begin{array}{c}\text { Poly(trimethylene carbonate } \\
\text { dimethacrylate) hydrogel } \\
\text { (PTMC-dMA) }\end{array}$ & physical & $1.04 \pm 0.04$ & $0.46 \pm 0.07$ & $159 \pm 43$ & {$[96]$} \\
\hline
\end{tabular}

\section{Bio-inspiration for strong interface formation}

The common methods for polymer-polymer hybrid systems preparation are either by physical and/or chemical interactions creating interlinks (strong bonds) or topological entanglements. Different chemicals such as silane coupling agents [27], cyanoacrylates [97] and benzophenone [98], have been used to create chemical bonds between distinctly different polymers. An interesting approach has been developed by nature to create strong bonds between different surfaces. For instance, synthetic adhesives bio-inspired from marine organism like mussels gained great attraction due to their suitability for saline and watery environments, as well as their high adhesive strength [99][100][101]. These adhesives show really high bonding strengths with various substrates, due to research progress in isolation and characterization of mussels main adhesive components increased the usage in medical applications such as dental and surgical glues [102][103]. The main adhesive compound in mussels is 3,4-dihydroxyphenylalanine (DOPA) which contains catechol units to create covalent and non-covalent interactions to many different surfaces Figure 6 [104]. 


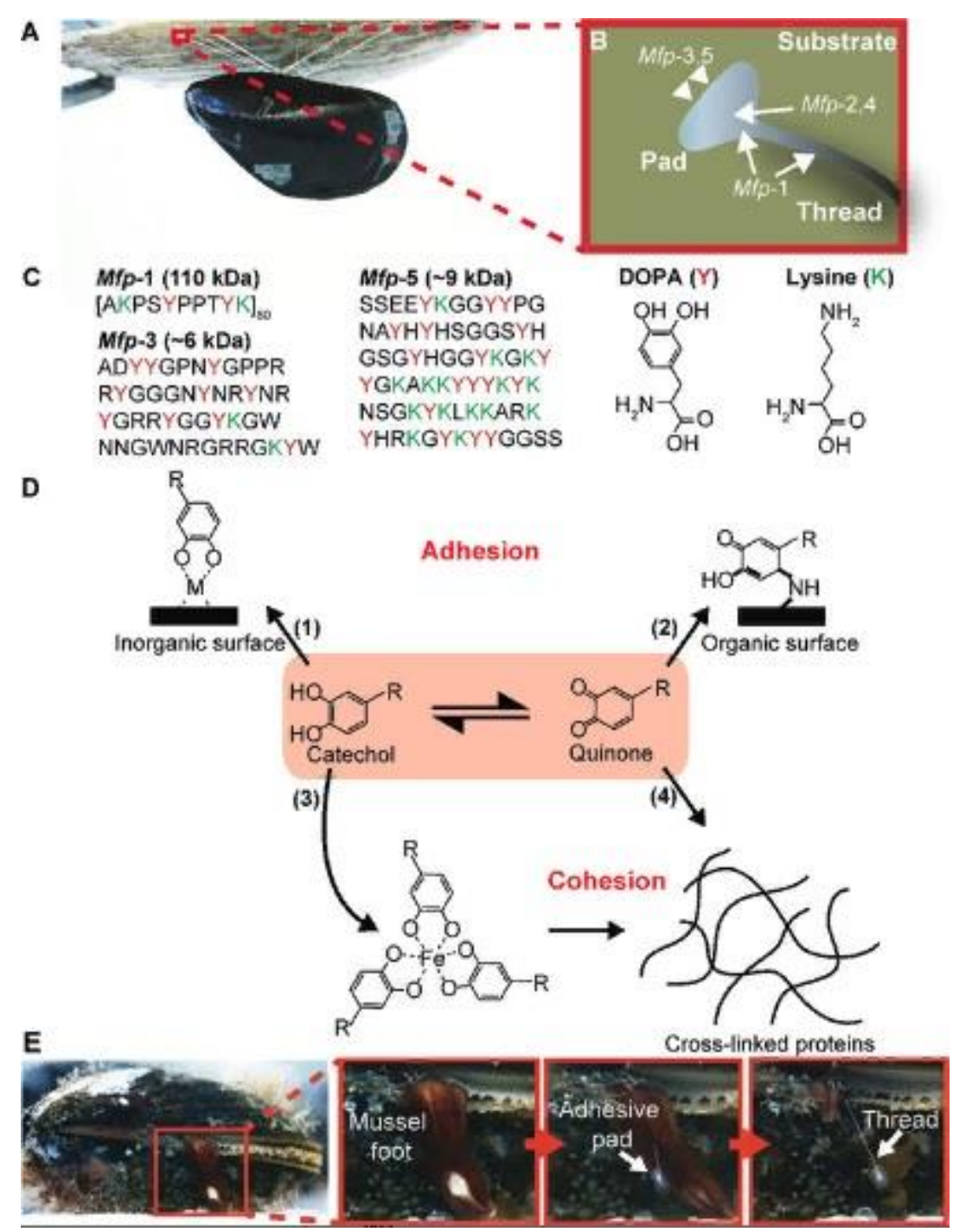

Figure 6. A) Blue mussel attached to a solid substrate (another mussel shell) using its byssal threads. Photo credit MSc Simon Frølich (Aarhus University). B) Bio-distribution of mussel foot proteins (mfp's) in the byssal thread and pad. C) Primary amino acid sequence of mfp-1, mfp-3 and mfp-5 (Y: DOPA, K: Lysine) D) Scheme showing examples of the adhesive and cohesive properties of catecholcontaining proteins. $R$ represents the remainder of the mfp's. E) Time-lapse photography showing the molding of a byssal thread (molding time $\approx 5 \mathrm{~min}$ ). Reproduced from [104] with permission. Copyright (C) 2016 WILEY-VCH Verlag GmbH \& Co. KGaA, Weinheim

Geckos' feet ability to adhere the tough surfaces has inspired researchers to fabricate tissue adhesives by mimicking its nano-scaled fibrillar arrays structure in the bottom of Geckos' feet. Those fibrillar arrays maximize the interfacial adhesion to surfaces by capillary forces and van der Waals interactions $[105,106]$. However, the created adhesion is not permanent especially to the wet surfaces. Therefore, Mahdavi et.al. have developed Gecko-inspired biodegradable tissue adhesive consisting oxidized-dextran aldehydes (DXTA) coated on nano-patterned poly(glycerol sebacate acrylate) (PGSA) produced by photolithography and reactive ion etching for medical therapies. The adhesion results showed that the fabricated DXTA-PGSA hybrid showed 2-fold higher adhesion than PGSA without DXTA [105].

Another example of bio-inspiration is from the mucilage of the aquatic plant Brasenia Schreberi to protect itself from herbivores. The plant creates polysaccharide gel nanosheets with low coefficient of friction (CoF) (0.005) when absorbed on glass substrates [107][108]. Healthy human body joints can provide the similar CoF. Due to the CoF similarity between the plant and human body, sustainable wear 
resistant materials and lubricants can be fabricated, effectively [109]. Overall, interfacial adhesion enhances the material interactions with cells and can promote proliferation and tissue recovery.

The team of Nicholas Jun-An Chan and Dunyin Gu, inspired by the natural spider silk which exhibits very good mechanical properties due to $\beta$-sheets secondary structures, has created a material consisting of more $\beta$-sheets thanks to the use of grafting-from polymerization. Due to the polymerization with $\mathrm{N}$-carboxyanhydride, the ring-opening reaction enabled the spatially controlled growth of poly(valine) and poly(valine-r-glycine) which are components of the secondary $\beta$-sheet. The results showed that the created network has significantly better compressive strength and stiffness being a 300 - and 100 -fold improved over the original network. Additionally, the hybrid network has demonstrated the resistance to acids, bases and protein denaturants [110].

These few examples clearly demonstrate that nature offers a great model for the development of strong interfaces between different surfaces/materials/system.

\section{Advancements in polymer-polymer hybrid systems for medical applications}

Polymer-polymer hybrid systems based on elastomers and hydrogels are gaining increased interest for medical applications due to unique combination of properties, often emulating live organisms function and performance. Some of sophisticated properties found in biomimetic materials will be discussed with emphasis on bioadhesiveness, injectability, antibacterial properties, biodegradability, porosity all important for medical applications (Figure 7).

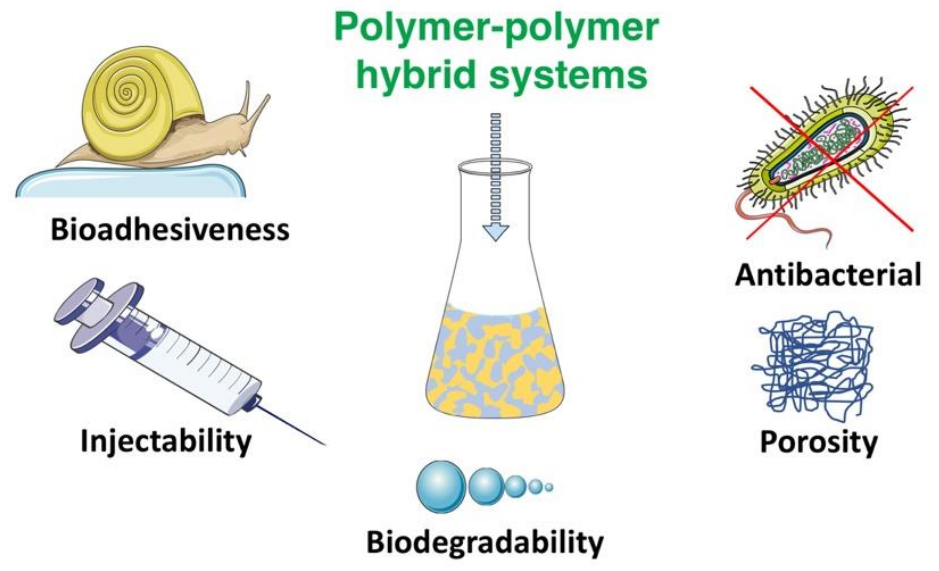

Figure 7. Functions and performance of polymer-polymer hybrid systems

\subsection{Bioadhesiveness}

Most of the medical applications, especially surgical procedures, require tissue adhesives and sealants, and hemostatic agents [111][112]. Those bioadhesives are mostly a glue to bind the tissues, seal the gaps or cracks and initiate the formation of blood clothes to stop bleeding, respectively [113][114]. With the development of material science, the compounds which show adhesive properties have been introduced by physical or chemical processes into the patches or scaffolds. This approach has gained successful outcomes in medical applications thanks to adhesion ability of those materials to various tissues such as soft, bone and skin [115][116][117][118]. Components of a hybrid system can act fully or partially as bioadhesive depending on interacting functional groups (Figure 8). 


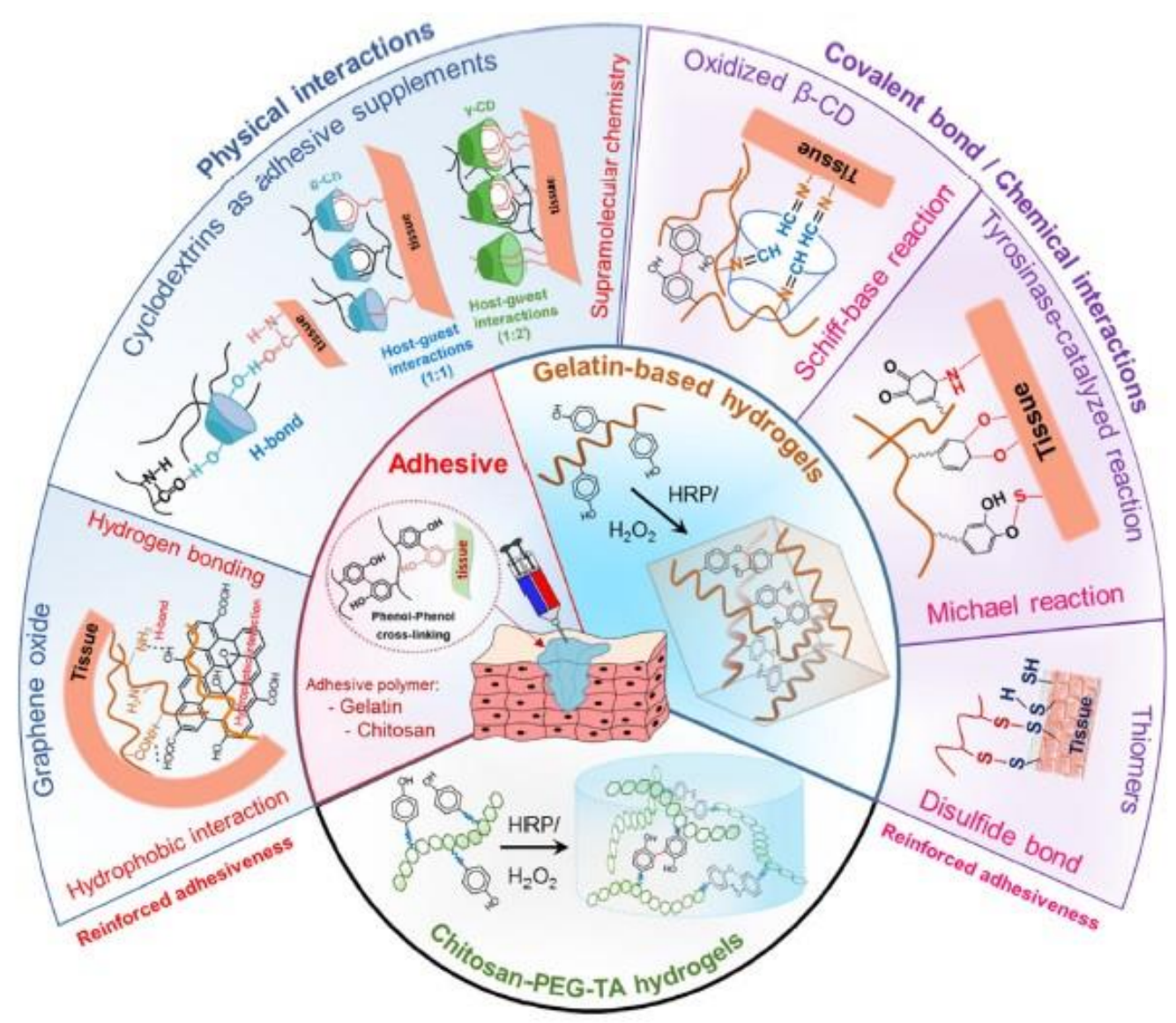

Figure 8. Development strategy of in situ forming horseradish peroxidase (HRP) catalyzed hydrogels with significantly enhanced adhesiveness through polymer choices and additional crosslinking. Reproduced from [111] with permission. (C) 2019 The Korean Society of Industrial and Engineering Chemistry. Published by Elsevier B.V. All rights reserved.

Recently, bioinspired adhesives have attracted great attention due the combination of natural functionality realized through synthetic approaches. For instance, mussels show extremely good adhesion with high binding strength to various surfaces under wet conditions [119][120][121]. The catechol unit is the main reason to allow mussels to adhere on a variety of surfaces [122][123]. Materials containing catechol units can be used to create covalent and non-covalent attachments to various substrates for many medical applications, including drug delivery systems and wound healing [124][125][126]. Figure 9 shows a hydrogel/polymeric nanoparticle (NP) hybrid systems to enhance localized antimicrobial drug delivery [127]. In this study, dopamine methacrylamide (DMA) containing catechol functional group was used as an adhesive moiety.

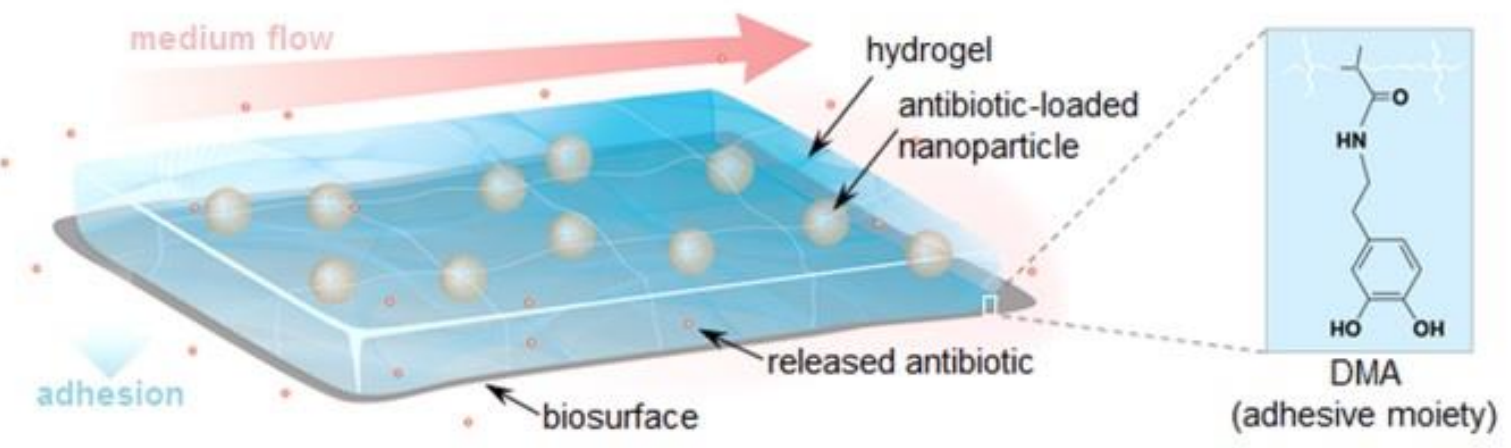


Figure 9. Schematic illustration of such adhesive NP-hydrogel system for localized antibiotic release to inhibit bacterial growth under flow conditions. Reproduced from [127] with permission. Copyright (C) 2016, American Chemical Society

\subsection{Injectability}

Traditional surgeries are increasingly being replaced by less invasive methods that shorten an overall procedure and patient's recovery time. Especially, in drug delivery and tissue engineering focus is being given to improve material's performance by their injectability [128]. The injectable systems can efficiently deliver particles such as drugs (antibiotics, anaesthetics), biomolecules (fibrin), fillers (silica nanoparticles) or genes (DNA, siRNA) [129]. Recent research of $X u$ et al. has focused on photocrosslinkable hydrogel for cartilage regeneration. Cartilage decellularized extracellular matrix (CDEM)polyhyaluronic acid (CDEM-pHA) cross-linked by UV radiation enables easy insertion of cells to obtain a scaffold that provides the cartilage tissue microenvironment. As the result, an effective regeneration of cartilage after combining the hydrogel with chondrocytes has been observed [130]. Another attractive model developed by $L i$ et al. is an injectable probe for measuring oxygen in tissues [131]. Hydrogels containing $\mathrm{N}$-isopropylacrylamide copolymer macromers for mesenchymal stem cell (MSC) delivery allow the formation of bone bridges, promoting the viability of MSCs, and can be used to create hard tissues due to gelatin microparticles (GMP) which are enzymatically digestible porogens and sites for cells attachment [132]. Photocrosslinked poly(ethylene glycol)-poly(lactide) (PEG-PLA) is hydrolytically stable and exhibit good mechanical properties. Studies show that after 45 days, due to the high density of chemical and physical cross-linking, they are still resistant to degradation and dissolution, and therefore are considered as a promising material for long-term controlled drug delivery [133]. Another long-term persistent hydrogel is the photo-crosslinked material composed of a double-network of modified sodium alginate and gelatin created by the Schiff base reaction [134]. Collectively, different works clearly demonstrated huge potential of injectable materials for biomedical applications. Xu et. al., produced an injectable hybrid system consisting hyperbranched multi-acrylated poly(ethylene glycol) macromers (HP-PEGs) and thiolated hyaluronic acid (HA-SH) and used it as a stem cell delivery for diabetic wound healing (Figure 10) [135]. It is also worth to note that new injectable and photocurable elastomers containing fatty acid derivatives [136] can be successfully used for minimally invasive surgical protocols in repair of small hernia defects (Figure 11) [137].

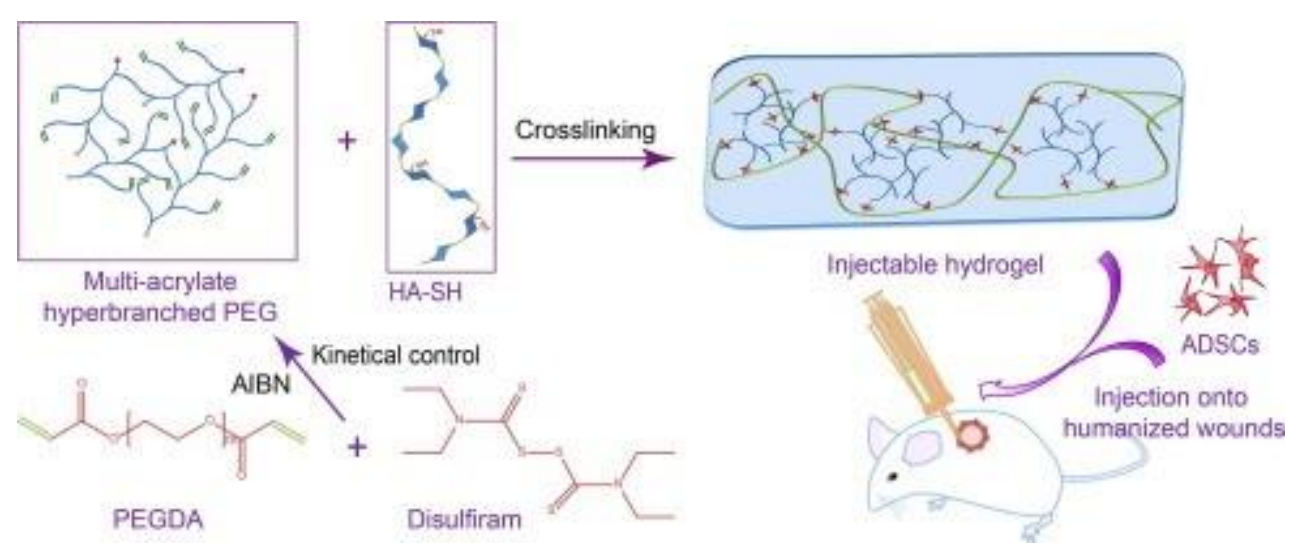

Figure 10. Schematic presentation of encapsulated adipose-derived stem cells (ADSCs) by an injectable hybrid hydrogel. Reproduced from [135] with permission. (c) 2018 Acta Materialia Inc. Published by Elsevier Ltd. All rights reserved. 


\section{Photocurable elastomer}

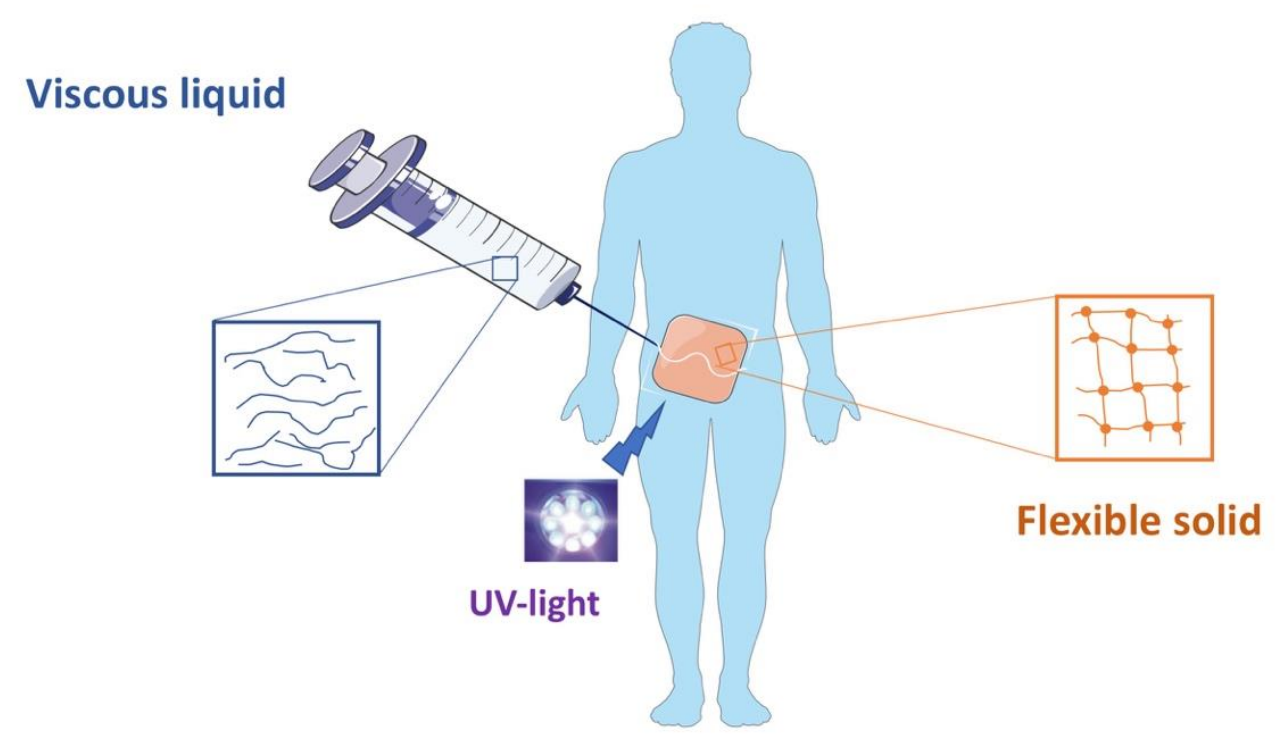

Figure 11. Schematic of injectable photocurable elastomer patch for small hernia repair.

\subsection{Biodegradability}

Biodegradable polymer-polymer hybrid materials are now tending to become the most commonly used materials in medical applications due to their gradual bio-resorption in the human body [138]. However, it should be considered that the degradation rate must be consistent with the healing and regeneration process. Various crosslinks density, crosslinking mechanism and components type were applied to control the degradation rate of such systems [139][140]. The most commonly used biodegradable materials are consisting homo- or copolymers of alpha-hydroxy acids, such as lactic and/or glycolic acids.

Biodegradation can be triggered by water (hydrolytic degradation) or/and enzymes (enzymatic degradation) within the body. Chemical structure of a polymer has the greatest influence on the type of degradation. Another important factors are chemical composition, type of crosslinking bonds, molecular weight and its distribution, porosity, stereochemistry and chain mobility [141]. Hybrid systems structured by synthetic bioelastomers usually tend to hydrolytic biodegradation due to their molecular chain structures sensitive to water (Figure 12). Hydrolysis of ester bonds usually leads to creation of carboxyl and hydroxyl end groups, whereas natural biomaterials tend to degrade enzymatically. 
1)<smiles>[R]C([R])=O</smiles>

ester<smiles>[R]NC(=O)O[R]</smiles>

urethane<smiles>[R]C(=O)OC([R])=O</smiles>

anhydride

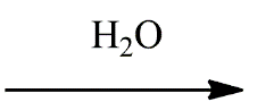<smiles>[R]C(=O)O</smiles>

carboxylic acid $+\quad \mathrm{R}^{1} \mathrm{OH}$

alcohol
2)

3)

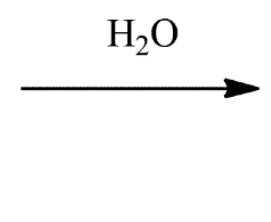

Figure 12. Hydrolytic degradation of common bioelastomers

The injected and/or implanted polymer-polymer hybrids can be degraded by oxidative (catalases, horseradish peroxidase and xanthine oxidase) or hydrolytic (protease, hydrolase, phosphatases, lipase and esterase) enzymes when exposed to body fluids and tissues [142][143][144]. Inflammatory cells (e.g. macrophages and leukocytes) create reactive oxygen species such as hydrogen peroxide, superoxide and nitric oxide during the inflammatory response to foreign materials [145]. Polymerpolymer hybrids can be cut up by those species which are contributing to material degradation whereas the hydrolytic enzymes hydrolyze the components of the hybrid network to help in the absorption of nutrients and solutes.

For instance, polycaprolactone (PCL)/gelatin(Gel) scaffold (sublayer) was electrospun on a dense polyurethane (PU)/propolis(EEP) (top layer) membrane to fabricate a bilayer wound dressing. It was demonstrated that polymer-polymer hybrid system combining synthetic polymer with natural one can enhance the stability of the scaffold. Hydrolytic and enzymatic degradation studies showed that PU/EEP membrane exhibited slower degradation rate in comparison with PCL/Gel hybrid structure. In the case of hydrolytic degradation, the total mass loss after 28 days for PU/EEP and PCL/Gel was found $1.9 \%$ and $76 \%$, respectively [146].

In another example, Remya et al. synthesized hybrid systems by modifying PCL with different molecular ratios of water soluble polymer PEO using electrospinning technique to create scaffolds. The weight loss for pure PCL was $8.5 \%$ whereas for PCL/PEO blends with $50: 50$ ratios and differing in molecular weight of PEO (10k g/mol vs $60 \mathrm{~kg} / \mathrm{mol})$, the weight loss was $41.7 \%$ and $48.7 \%$, respectively after 3 months. The study also showed that the properties of PCL scaffolds such as cell viability, mechanical properties and hydrophilicity were increased by incorporation of PEO and these materials can be possible candidates for bone tissue engineering applications [147].

\subsection{Porosity}

The porosity is an important feature in medical applications, especially in scaffolds [148][149]. The pore architecture and interconnectivity have beneficial role in proliferation, cell survival and migration to create functional materials, and secrete ECM. Therefore, scaffold porosity is a must for homogenous 
cell distribution and interconnection throughout engineered tissues [150][151]. Additionally, pore size can have an effect on the cell growth, vascularization, nutrients and oxygen diffusion, especially in the absence of a functional vascular systems [152][153][154]. Various techniques, components and ratios are used to obtain controlled pore size and architecture scaffolds. For instance, Kanimozhi et al. prepared chitosan/poly(vinyl alcohol)/carboxymethyl cellulose (CP-CMC) porous scaffold by simple freeze drying and salt leaching techniques. Among scaffolds, 1:1 weight ratios showed significantly high porosity as compared to other ratios. Incorporation of CMC enhanced the scaffold porosity from $50 \%$ to $90 \%$ by increasing the molar ratio of CMC. But when comparing the freeze dried scaffolds and salt leached scaffolds of 1:1 weight ratio, the 50\% CP:50\% CMC material showed higher porosity of $90 \%$ in salt leached and $70 \%$ in freeze dried scaffolds, respectively. The reason is explained that as with the increasing of $\mathrm{CMC}$ ratio, the actual volume occupied by the molecules decreases [155].

In another study, Morris et al. produced porous hybrid scaffolds of chitosan/polyethylene glycol diacrylate (CS/PEGDA) using 3D bioprinting by stereolithography method to create internal pore and macroscopic shapes. They achieved varied pore sizes by changing the CS molecular weight ratios. For instance, the average pore size of the pure PEGDA scaffolds increased from $24 \%$ to $67 \%$ by the addition of low molecular weight CS (LMWCS) $\left(M_{W}=50-190 \mathrm{kDa}\right.$ ) in the scaffold with the ratio LMWCS:PEGDA at 1:7.5. These kind of studies show that controlled pore size and architecture can be achievable for the specific needs in medical applications [156].

\subsection{Antibacterial surfaces}

Antibacterial materials, especially surfaces, are playing an important role in protecting from contamination and eliminating bacteria from skin tissue and surface of medical devices and implants. Bacterial adhesion is the main cause to create the 3D biofilm complex structures which infects the surrounding tissues. Therefore, new strategies which eliminate biofilm-based issues are applied. Hence, polymer-polymer hybrid systems which contains antibacterial components are developed. For instance, Piarali et al. have fabricated a fiber mesh based on surface modification of polyhydroxyalkanoate by electrospinning technique for tissue regeneration. In this study, basically hybrid system was created by a synthetic antimicrobial peptide with anti-biofilm and strong bactericidal properties [157].

In another study, Muzammil et al. have created polymer-polymer hybrids scaffolds containing castor oil reinforced chitosan with various hydrophilic polymers in a hydrogel form. The obtained polymer hybrids showed antibacterial and hemostatic activities with good mechanical properties. Therefore, such systems can be a good candidate for skin tissue regeneration and wound healing applications. [158].

\section{Hybrid systems for drug delivery and tissue engineering}

The development of advanced hybrid materials for medical applications has been widely studied over the last years. Specific interactions between the components, combination of raw material advantages and molecular organization of these systems dictates the direction of the medical applications. Different systems which combine different classes of polymers in one material, such as proteins and lipids, with large yield formulations and many advantages, such as high interaction with targets to enhance their performance have been effectively developed.

Amphiphilic hybrid systems containing lipids and polymers are used commonly for drug delivery systems (DDS). Figure 13 shows comparison of the structure of some types of traditional DDS and the respective hybrid systems [159][160][161][162]. 

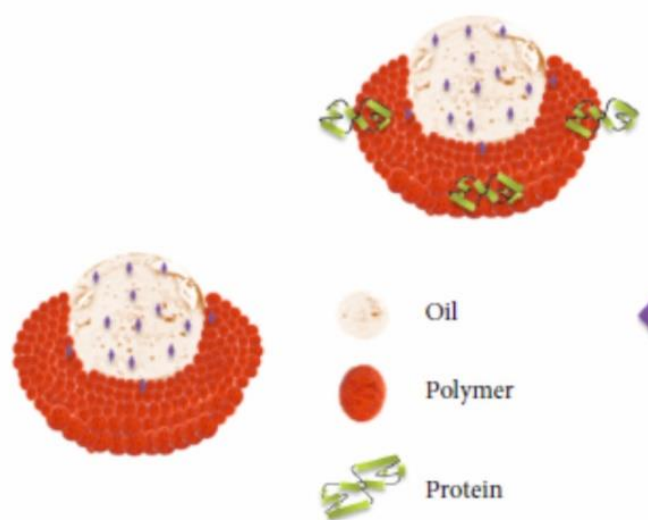

Oil
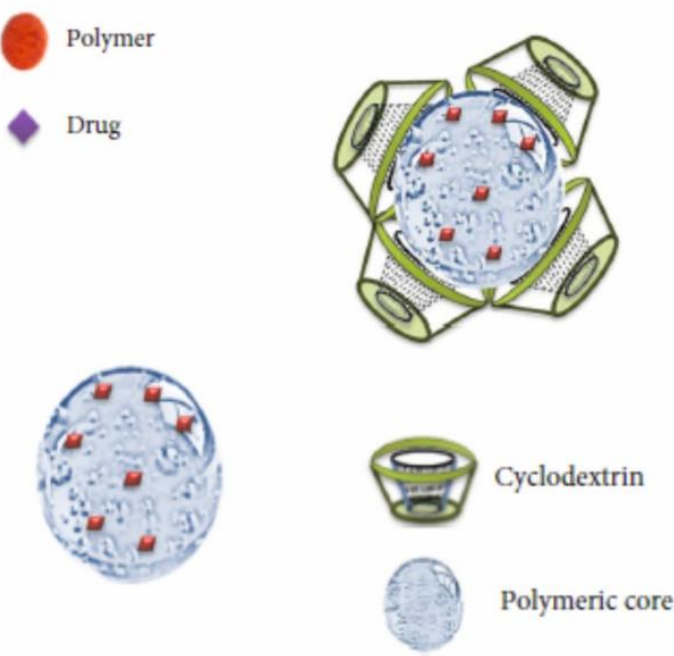

Polymeric core

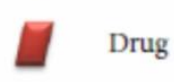

Drug
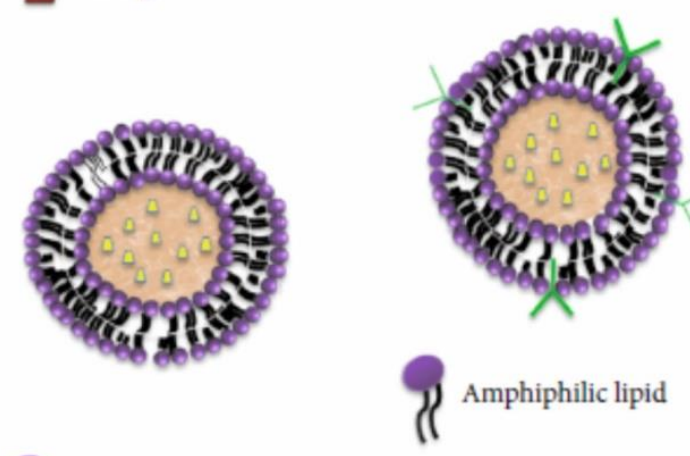

Q Amphiphilic lipid

Drug

Drug

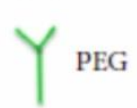

(a)

(b)

Figure 13. Schematic representation of some traditional nanocarriers' structures (a) and their respective organic biohybrid systems (b). Reproduced from [159] with permission. Copyright (C) 2017 Lígia N. M. Ribeiro et al. 
Poly(lactic-co-glycolic acid) (PLGA) is a key polymer in the formulations of DDS for medical applications due to its biocompatibility, biodegradability, biosafety and versatility in formulation and functionalization Figure 14 [163].
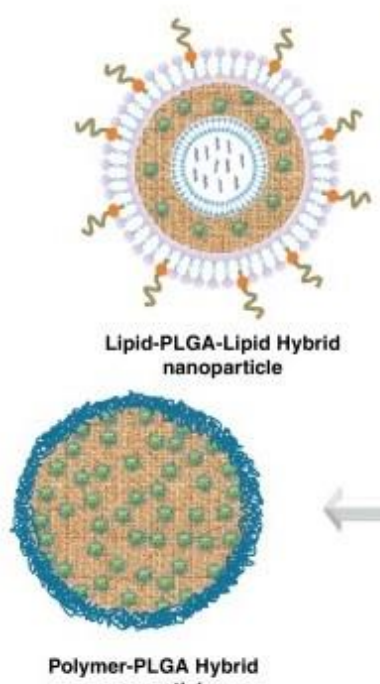
nanoparticle

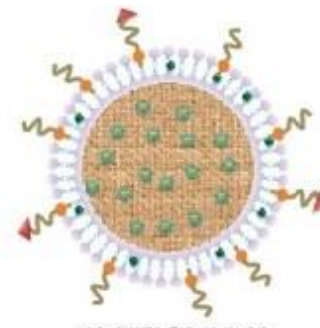

Lipid-PLGA Hybrid nanoparticle 4 Lipid-PLGA-Polymer Hybrid
nanoparticle $\sum_{\substack{\text { Lipid-PLGA-Polymer Hybrid } \\ \text { nanoparticle }}}^{2}$
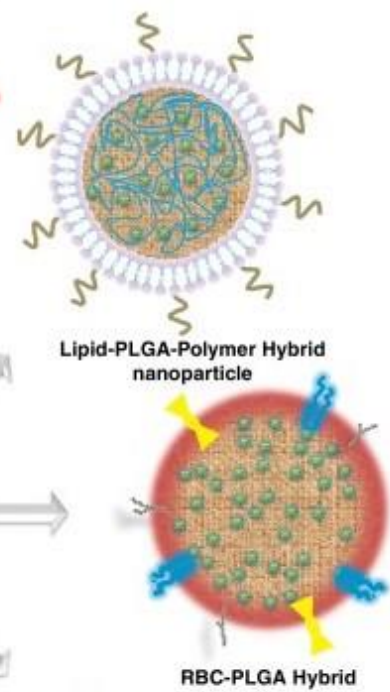

Figure 14. An overview of major hybrid poly(lactic-co-glycolic acid)(PLGA) nanoparticles. Abbreviations: PEG, polyethylene glycol; RBC, red blood cells; siRNA, short-interfering RNA. Reproduced from [163] with permission. Copyright (C) 2014 Elsevier Ltd. All rights reserved.

Another medical application of polymer-polymer hybrid systems is tissue engineering. Hybrid systems play an important role in the success of tissue engineering approaches, as they guide the structure of developing tissues, gaining mechanical and physical stability, and migrating cells or delivering the molecules to transplanted. Those highly efficient polymer hybrid systems find applications in bone, neural and cardiac tissue engineering [26][163][164][165][166][167][168] (Figure 15). 


\section{Conductive components}

Forms

\section{Application}

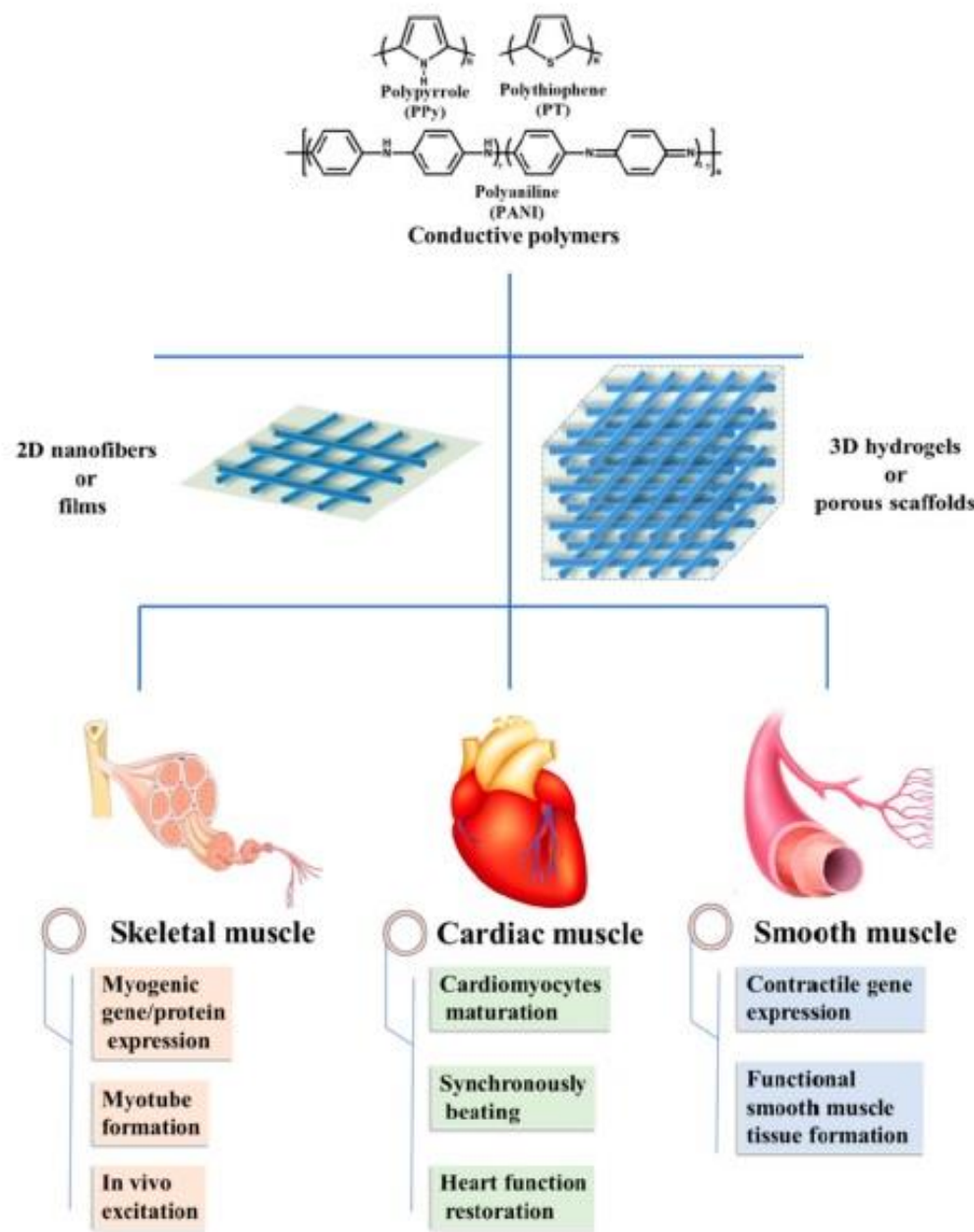

Figure 15. Main conductive materials, scaffold forms, and applications in muscle tissue engineering. Reproduced from [168] with permission. Copyright (C) 2020 Omid Yousefzade et al.

\section{Conclusions and perspectives}

Inspiration from nature is a driving force in development of various functional structures, including polymer-polymer hybrid systems of great promise for medical applications. Recent advancements in (nano)materials science show that the rational designed of hybrid systems can result in highly functional hybrids of good adhesion strength, injectability and desired biological properties for specific medical application. Variety of bioelastomers and hydrogels for the creation of polymerpolymer hybrid systems continues to grow, and highly advanced materials are needed to be fabricated to fulfill all requirements of medical industry. Bio-inspired materials obtained from natural-resources based elastomers, including fatty acids, have the benefits in biocompatibility and biodegradability at simultaneous optimal physico-chemical and mechanical properties. In addition, natural hydrogels can overcome potential long-term side effects of synthetic materials since biodegradation products are non-toxic and biocompatible. Thus, future efforts should concentrate on better understanding of interactions of those materials with natural body tissues, thus opening new chapters in bio-inspired materials science and engineering. Finally, such advanced bio-inspired polymer-polymer hybrid systems may lead to the production of a novel classes of materials on a commercial scale that are easily processable, highly biofunctional and easily applicable/administrated. 


\section{Declaration of Competing Interest}

The authors declare no conflict of interest.

\section{Acknowledgements}

This work has been financially supported by Polish National Science Center (Grant number: UMO2019/33/B/ST5/01445).

\section{References:}

[1] S. Vijayavenkataraman, W. C. Yan, W. F. Lu, C. H. Wang, and J. Y. H. Fuh, "3D bioprinting of tissues and organs for regenerative medicine," Adv. Drug Deliv. Rev., vol. 132, pp. 296-332, 2018, doi: 10.1016/j.addr.2018.07.004.

[2] Y. Teramura, K. N. Ekdahl, and A. Barbu, "A hybrid of cells and pancreatic islets toward a new bioartificial pancreas," Regen. Ther., vol. 3, pp. 68-74, 2016, doi: 10.1016/j.reth.2016.03.004.

[3] R. D. Abbott and D. L. Kaplan, "Engineering Biomaterials for Enhanced Tissue Regeneration," Curr. Stem Cell Reports, vol. 2, no. 2, pp. 140-146, 2016, doi: 10.1007/s40778-016-0039-3.

[4] B. T. Zhiqiang Luo, Dara E. Weiss, Qingyun Liu, "Biomimetic Approaches Toward Smart Biohybrid Systems," Physiol. Behav., vol. 176, no. 5, pp. 139-148, 2017, doi: 10.1007/s12274018-2004-1.Biomimetic.

[5] R. Walia et al., "Hydrogel-Solid Hybrid Materials for Biomedical Applications Enabled by Surface-Embedded Radicals," Adv. Funct. Mater., vol. 30, no. 38, pp. 1-16, 2020, doi: 10.1002/adfm.202004599.

[6] D. Ozdil and H. M. Aydin, "Polymers for medical and tissue engineering applications," J. Chem. Technol. Biotechnol., vol. 89, no. 12, pp. 1793-1810, 2014, doi: 10.1002/jctb.4505.

[7] X. Song and J. Li, Functional Hydrogels as Biomaterials, vol. 12. 2018.

[8] M. P. Lutolf and J. A. Hubbell, "Synthetic biomaterials as instructive extracellular microenvironments for morphogenesis in tissue engineering," Nat. Biotechnol., vol. 23, no. 1, pp. 47-55, 2005, doi: 10.1038/nbt1055.

[9] S. Sahoo, C. Chung, S. Khetan, and J. A. Burdick, "Hydrolytically degradable hyaluronic acid hydrogels with controlled temporal structures," Biomacromolecules, vol. 9, no. 4, pp. 10881092, 2008, doi: 10.1021/bm800051m.

[10] F. Faÿ, D. Carteau, I. Linossier, M. Delbury, and K. Vallée-Réhel, "Joint-action of antifouling substances in copper-free paints," Colloids Surfaces B Biointerfaces, vol. 102, pp. 569-577, 2013, doi: 10.1016/j.colsurfb.2012.08.055.

[11] A. Al-Huseini, R. Kasi, A. Shafaamri, I. A. Wonnie Ma, and R. Subramaniam, "Study of the physical and electrochemical properties of hybrid paint system based on zinc-rich primer for mild steel protection," Pigment Resin Technol., vol. 49, no. 1, pp. 33-40, 2020, doi: 10.1108/PRT-09-2018-0101.

[12] F. Scheaua, "Modelling of the visco-elastic pendular hybrid system with dissipative rolling 
elements," IOP Conf. Ser. Mater. Sci. Eng., vol. 591, no. 1, 2019, doi: 10.1088/1757$899 X / 591 / 1 / 012029$.

[13] V. Hass et al., "Correlation between degree of conversion, resin-dentin bond strength and nanoleakage of simplified etch-and-rinse adhesives," Dent. Mater., vol. 29, no. 9, pp. 921928, 2013, doi: 10.1016/j.dental.2013.05.001.

[14] S. Vandekerckhove and M. D'Hooghe, "Exploration of aziridine- and $\beta$-lactam-based hybrids as both bioactive substances and synthetic intermediates in medicinal chemistry," Bioorganic Med. Chem., vol. 21, no. 13, pp. 3643-3647, 2013, doi: 10.1016/j.bmc.2013.04.033.

[15] S. Matsumura et al., "Injectable PEGylated fibrinogen cell-laden microparticles made with a continuous solvent- and oil-free preparation method," J. Polym. Sci. Part A Polym. Chem., vol. 13, pp. 78-87, 2008, doi: 10.1002/pola.

[16] Q. Cheng, X. Guo, X. Hao, Z. Shi, S. Zhu, and Z. Cui, "Fabrication of Robust Antibacterial Coatings Based on an Organic-Inorganic Hybrid System," ACS Appl. Mater. Interfaces, vol. 11, no. 45, pp. 42607-42615, 2019, doi: 10.1021/acsami.9b15031.

[17] H. K. S. Yadav, N. Anwar, A. Halabi, and G. A. Alsalloum, "Nanogels as Novel Drug Delivery Systems - A Review Properties of Nanogels Keywords : Introduction Advantages of Nanogels," Insight Pharma Res., vol. 1, no. 1, pp. 1-8, 2017.

[18] C. Xu et al., "Optimizing Anisotropic Polyurethane Scaffolds to Mechanically Match with Native Myocardium," ACS Biomater. Sci. Eng., vol. 6, no. 5, pp. 2757-2769, 2020, doi: 10.1021/acsbiomaterials.9b01860.

[19] N. R. Richbourg, N. A. Peppas, and V. I. Sikavitsas, "Tuning the biomimetic behavior of scaffolds for regenerative medicine through surface modifications," J. Tissue Eng. Regen. Med., vol. 13, no. 8, pp. 1275-1293, 2019, doi: 10.1002/term.2859.

[20] J. M. Olbrich et al., "Injectable in situ forming controlled release implant composed of a polyether-ester-carbonate and applications in the field of chemotherapy," J. Biomed. Mater. Res. Part A, vol. 100 A, no. 9, pp. 2365-2372, 2012, doi: 10.1002/jbm.a.34179.

[21] I. Manavitehrani, A. Fathi, H. Badr, S. Daly, A. N. Shirazi, and F. Dehghani, "Biomedical applications of biodegradable polyesters," Polymers (Basel)., vol. 8, no. 1, 2016, doi: 10.3390/polym8010020.

[22] A. S. Hoffman, "Hydrogels for biomedical applications," Adv. Drug Deliv. Rev., vol. 64, no. SUPPL., pp. 18-23, 2012, doi: 10.1016/j.addr.2012.09.010.

[23] C. Sanchez, B. Julián, P. Belleville, and M. Popall, "Applications of hybrid organic-inorganic nanocomposites," J. Mater. Chem., vol. 15, no. 35-36, pp. 3559-3592, 2005, doi: 10.1039/b509097k.

[24] R. Shi et al., "Recent advances in synthetic bioelastomers," Int. J. Mol. Sci., vol. 10, no. 10, pp. 4223-4256, 2009, doi: 10.3390/ijms10104223.

[25] Y. Zhang et al., "Soybean-Oil-Based Thermosetting Resins with Methacrylated Vanillyl Alcohol as Bio-Based, Low-Viscosity Comonomer," Macromol. Mater. Eng., vol. 303, no. 1, pp. 1-10, 2018, doi: 10.1002/mame.201700278.

[26] G. G. Lin and J. G. Scott, "Hybrid Multicomponent Hydrogels for Tissue Engineering Xinqiao," Macromol. Biosci., vol. 9, no. 2, pp. 140-156, 2009, doi: 10.1002/mabi.200800284.Hybrid.

[27] Q. Liu, G. Nian, C. Yang, S. Qu, and Z. Suo, "Bonding dissimilar polymer networks in various manufacturing processes," Nat. Commun., vol. 9, no. 1, pp. 1-11, 2018, doi: 10.1038/s41467- 
018-03269-x.

[28] P. Król, "Synthesis methods, chemical structures and phase structures of linear polyurethanes. Properties and applications of linear polyurethanes in polyurethane elastomers, copolymers and ionomers," Prog. Mater. Sci., vol. 52, no. 6, pp. 915-1015, 2007, doi: 10.1016/j.pmatsci.2006.11.001.

[29] B. Amsden and B. Amsden, "Curable, biodegradable elastomers : emerging biomaterials for drug delivery and tissue engineering," pp. 1335-1348, 2007, doi: 10.1039/b707472g.

[30] Y. M. Hassouna, S. Zamani, W. Kafienah, and H. M. Younes, "Synthesis, characterization \& cytocompatibility of poly (diol-co-tricarballylate) based thermally crosslinked elastomers for drug delivery \& tissue engineering applications," Mater. Sci. Eng. C, vol. 93, no. July, pp. 254264, 2018, doi: 10.1016/j.msec.2018.07.028.

[31] D. M. Opris, "Polar Elastomers as Novel Materials for Electromechanical Actuator Applications," Adv. Mater., vol. 30, no. 5, pp. 1-23, 2018, doi: 10.1002/adma.201703678.

[32] C. Xu et al., "Development of dopant-free conductive bioelastomers," Sci. Rep., vol. 6, no. June, pp. 1-13, 2016, doi: 10.1038/srep34451.

[33] T. Mirfakhrai, J. D. W. Madden, and R. H. Baughman, "Polymer artificial muscles," Mater. Today, vol. 10, no. 4, pp. 30-38, 2007, doi: 10.1016/S1369-7021(07)70048-2.

[34] K. H. Jeong, J. Kim, and L. P. Lee, "Biologically inspired artificial compound eyes," Science (80-. )., vol. 312, no. 5773, pp. 557-561, 2006, doi: 10.1126/science.1123053.

[35] Q. Wen, S. M. Mithieux, and A. S. Weiss, "Elastin Biomaterials in Dermal Repair," Trends Biotechnol., vol. 38, no. 3, pp. 280-291, 2020, doi: 10.1016/j.tibtech.2019.08.005.

[36] K. L. Christman, A. J. Vardanian, Q. Fang, R. E. Sievers, H. H. Fok, and R. J. Lee, "Injectable fibrin scaffold improves cell transplant survival, reduces infarct expansion, and induces neovasculature formation in ischemic myocardium," J. Am. Coll. Cardiol., vol. 44, no. 3, pp. 654-660, 2004, doi: 10.1016/j.jacc.2004.04.040.

[37] Q. Z. Chen, S. E. Harding, N. N. Ali, A. R. Lyon, and A. R. Boccaccini, "Biomaterials in cardiac tissue engineering: Ten years of research survey," Mater. Sci. Eng. R Reports, vol. 59, no. 1-6, pp. 1-37, 2008, doi: 10.1016/j.mser.2007.08.001.

[38] E. Zeimaran, S. Pourshahrestani, I. Djordjevic, B. Pingguan-Murphy, N. A. Kadri, and M. R. Towler, "Bioactive glass reinforced elastomer composites for skeletal regeneration: A review," Mater. Sci. Eng. C, vol. 53, pp. 175-188, 2015, doi: 10.1016/j.msec.2015.04.035.

[39] Q. Chen, S. Liang, and G. A. Thouas, "Elastomeric biomaterials for tissue engineering," Prog. Polym. Sci., vol. 38, no. 3-4, pp. 584-671, 2013, doi: 10.1016/j.progpolymsci.2012.05.003.

[40] Y. Tian, K. Liang, X. Wang, and Y. Ji, "Fabrication of Nanocomposite Bioelastomer Porous Scaffold Based on Chitin Nanocrystal Supported Emulsion-Freeze-Casting," ACS Sustain. Chem. Eng., vol. 5, no. 4, pp. 3305-3313, 2017, doi: 10.1021/acssuschemeng.6b03146.

[41] B. Aghaei-Ghareh-Bolagh, S. M. Mithieux, and A. S. Weiss, "Elastic proteins and elastomeric protein alloys," Curr. Opin. Biotechnol., vol. 39, pp. 56-60, 2016, doi: 10.1016/j.copbio.2015.12.020.

[42] L. Li et al., "Recombinant Resilin-Based Bioelastomers for Regenerative Medicine Applications," Adv. Healthc. Mater., vol. 5, no. 2, pp. 266-275, 2016, doi: 10.1002/adhm.201500411. 
[43] P. Y. Chen, J. McKittrick, and M. A. Meyers, "Biological materials: Functional adaptations and bioinspired designs," Prog. Mater. Sci., vol. 57, no. 8, pp. 1492-1704, 2012, doi: 10.1016/j.pmatsci.2012.03.001.

[44] J. E. Puskas and Y. Chen, "Biomedical application of commercial polymyers and novel polyisobutylene-based thermoplastic elastomers for soft tissue replacement," Biomacromolecules, vol. 5, no. 4, pp. 1141-1154, 2004, doi: 10.1021/bm034513k.

[45] R. I. Litvinov and J. W. Weisel, "Fibrin mechanical properties and their structural origins," Matrix Biol., vol. 60-61, pp. 110-123, 2017, doi: 10.1016/j.matbio.2016.08.003.

[46] A. Zhmurov, A. E. X. Brown, R. I. Litvinov, R. I. Dima, J. W. Weisel, and V. Barsegov, "Mechanism of fibrin(ogen) forced unfolding," Structure, vol. 19, no. 11, pp. 1615-1624, 2011, doi: 10.1016/j.str.2011.08.013.

[47] L. Li, M. B. Charati, and K. L. Kiick, "Elastomeric polypeptide-based biomaterials," Polym. Chem., vol. 1, no. 8, pp. 1160-1170, 2010, doi: 10.1039/b9py00346k.

[48] C. Jennewein, N. Tran, P. Paulus, P. Ellinghaus, J. A. Eble, and K. Zacharowski, "Novel aspects of fibrin(ogen) fragments during inflammation," Mol. Med., vol. 17, no. 5-6, pp. 568-573, 2011, doi: 10.2119/molmed.2010.00146.

[49] E. K. Hejbøl, J. Sellathurai, P. D. Nair, and H. D. Schrøder, "Injectable scaffold materials differ in their cell instructive effects on primary human myoblasts," J. Tissue Eng., vol. 8, 2017, doi: $10.1177 / 2041731417717677$.

[50] R. Vendamme and W. Eevers, "Sticky Degradable Bioelastomers," Chem. Mater., vol. 29, no. 12, pp. 5353-5363, 2017, doi: 10.1021/acs.chemmater.7b01635.

[51] L. Vogt, L. R. Rivera, L. Liverani, A. Piegat, M. El Fray, and A. R. Boccaccini, “Poly( $\varepsilon-$ caprolactone)/poly(glycerol sebacate) electrospun scaffolds for cardiac tissue engineering using benign solvents," Mater. Sci. Eng. C, vol. 103, no. February, p. 109712, 2019, doi: 10.1016/j.msec.2019.04.091.

[52] V. Izraylit, O. E. C. Gould, T. Rudolph, K. Kratz, and A. Lendlein, "Controlling Actuation Performance in Physically Cross-Linked Polylactone Blends Using Polylactide Stereocomplexation," Biomacromolecules, vol. 21, no. 2, pp. 338-348, 2020, doi: 10.1021/acs.biomac.9b01279.

[53] Z. Li et al., "Supramolecular and Physically Double-Cross-Linked Network Strategy toward Strong and Tough Elastic Fibers," ACS Macro Lett., pp. 1655-1661, 2020, doi: 10.1021/acsmacrolett.0c00579.

[54] H. Martinez and M. A. Hillmyer, "Carboxy-telechelic polyolefins in cross-linked elastomers," Macromolecules, vol. 47, no. 2, pp. 479-485, 2014, doi: 10.1021/ma402397b.

[55] B. Amsden, S. Wang, and U. Wyss, "Synthesis and characterization of thermoset biodegradable elastomers based on star-poly ( $\varepsilon$-caprolactone-co-D,L-lactide)," Biomacromolecules, vol. 5, no. 4, pp. 1399-1403, 2004, doi: 10.1021/bm034538j.

[56] J. E. Puskas et al., "A nanostructured carbon-reinforced polyisobutylene-based thermoplastic elastomer," Biomaterials, vol. 31, no. 9, pp. 2477-2488, 2010, doi: 10.1016/j.biomaterials.2009.12.003.

[57] P. Hodge, R. O'Dell, M. S. K. Lee, and J. R. Ebdon, "Synthesis of polyesters by reaction of carboxylic acid quaternary ammonium salts with alkyl halides or alkyl tosylates," Polymer (Guildf)., vol. 37, no. 7, pp. 1267-1271, 1996, doi: 10.1016/0032-3861(96)80853-6. 
[58] A. Wcislek et al., "Enzymatic degradation of poly(butylene succinate) copolyesters synthesized with the use of Candida antarctica lipase B," Polymers (Basel)., vol. 10, no. 6, 2018, doi: $10.3390 /$ polym 10060688 .

[59] L. Liverani, A. Piegat, A. Niemczyk, M. El Fray, and A. R. Boccaccini, "Electrospun fibers of poly(butylene succinate-co-dilinoleic succinate) and its blend with poly(glycerol sebacate) for soft tissue engineering applications," Eur. Polym. J., vol. 81, pp. 295-306, 2016, doi: 10.1016/j.eurpolymj.2016.06.009.

[60] A. Sonsecaa, R. Sahaya, K. Stepiena, J. Bukalaa, A. Wcisleka, A. McClain, P. Sobolewski, X. Meng Sui, J. E. Puskas, J. Kohn, H. D. Wagner, M. El Fray, "Architectured helically coiled scaffolds from elastomeric poly(butylene succinate) (PBS) copolyester via wet electrospinning", Materials Science \& Engineering, 2020, doi:10.1016/j.msec.2019.110505

[61] Y. Zhou, X. Zhou, K. Liang, and Y. Ji, "Degradable Bioelastomers Prepared by a Facile Melt Polycondensation of Citric Acid and Polycaprolactone-diol," J. Macromol. Sci. Part B Phys., vol. 57, no. 10, pp. 679-690, 2018, doi: 10.1080/00222348.2018.1511296.

[62] J. Guo, D. Y. Nguyen, R. T. Tran, Z. Xie, X. Bai, and J. Yang, "Design Strategies and Applications of Citrate-Based Biodegradable Elastomeric Polymers," Nat. Synth. Biomed. Polym., pp. 259285, 2014, doi: 10.1016/B978-0-12-396983-5.00017-X.

[63] C. L. E. Nijst et al., "Synthesis and characterization of photocurable elastomers from poly(glycerol-co-sebacate)," Biomacromolecules, vol. 8, no. 10, pp. 3067-3073, 2007, doi: $10.1021 / \mathrm{bm} 070423 \mathrm{u}$.

[64] Y. Wang, Y. M. Kim, and R. Langer, "In vivo degradation characteristics of poly (glycerol sebacate)," J. Biomed. Mater. Res. - Part A, vol. 66, no. 1, pp. 192-197, 2003, doi: 10.1002/jbm.a.10534.

[65] L. Vogt, L. Liverani, J. A. Roether, and A. R. Boccaccini, "Electrospun zein fibers incorporating poly(glycerol sebacate) for soft tissue engineering," Nanomaterials, vol. 8, no. 3, pp. 1-16, 2018, doi: 10.3390/nano8030150.

[66] A. G. Mitsak, A. M. Dunn, and S. J. Hollister, "Mechanical characterization and non-linear elastic modeling of poly(glycerol sebacate) for soft tissue engineering," J. Mech. Behav. Biomed. Mater., vol. 11, pp. 3-15, 2012, doi: 10.1016/j.jmbbm.2011.11.003.

[67] D. Dippold, M. Tallawi, S. Tansaz, J. A. Roether, and A. R. Boccaccini, "Novel electrospun poly(glycerol sebacate)-zein fiber mats as candidate materials for cardiac tissue engineering," Eur. Polym. J., vol. 75, pp. 504-513, 2016, doi: 10.1016/j.eurpolymj.2015.12.030.

[68] C. Tallá Ferrer, G. Vilariño-Feltrer, M. Rizk, H. G. Sydow, and A. Vallés-Lluch, "Nanocomposites based on poly (glycerol sebacate) with silica nanoparticles with potential application in dental tissue engineering," Int. J. Polym. Mater. Polym. Biomater., vol. 69, no. 12, pp. 761-772, 2020, doi: 10.1080/00914037.2019.1616197.

[69] S. Yang, K. F. Leong, Z. Du, and C. K. Chua, "The design of scaffolds for use in tissue engineering. Part I. Traditional factors," Tissue Eng., vol. 7, no. 6, pp. 679-689, 2001, doi: 10.1089/107632701753337645.

[70] A. Baji, S. C. Wong, T. S. Srivatsan, G. O. Njus, and G. Mathur, "Processing methodologies for polycaprolactone-hydroxyapatite composites: A review," Mater. Manuf. Process., vol. 21, no2, pp. 211-218, 2006, doi: 10.1081/AMP-200068681. 
[71] C. Kanemura, S. Nakashima, and A. Hotta, "Mechanical properties and chemical structures of biodegradable poly(butylene-succinate) for material reprocessing," Polym. Degrad. Stab., vol. 97, no. 6, pp. 972-980, 2012, doi: 10.1016/j.polymdegradstab.2012.03.015.

[72] E. Hassan, Y. Wei, H. Jiao, and Y. Muhuo, "Dynamic mechanical properties and thermal stability of poly (lactic acid) and poly(butylene succinate) blends composites," J. Fiber Bioeng. Informatics, vol. 6, no. 1, pp. 85-94, 2013, doi: 10.3993/jfbi03201308.

[73] L. Liu, J. Yu, L. Cheng, and W. Qu, "Mechanical properties of poly(butylene succinate) (PBS) biocomposites reinforced with surface modified jute fibre," Compos. Part A Appl. Sci. Manuf., vol. 40, no. 5, pp. 669-674, 2009, doi: 10.1016/j.compositesa.2009.03.002.

[74] A. Gowman, T. Wang, A. Rodriguez-Uribe, A. K. Mohanty, and M. Misra, "Bio-poly(butylene succinate) and Its Composites with Grape Pomace: Mechanical Performance and Thermal Properties," ACS Omega, vol. 3, no. 11, pp. 15205-15216, 2018, doi: 10.1021/acsomega.8b01675.

[75] O. W. D. LíM, “Hydrophilic Gels for Biological Use," Nature, 1960.

[76] P. H. Corkhill, C. J. Hamilton, and B. J. Tighe, "Synthetic hydrogels VI. Hydrogel composites as wound dressings and implant materials," Biomaterials, vol. 10, no. 1, pp. 3-10, 1989, doi: 10.1016/0142-9612(89)90002-1.

[77] S. H. Aswathy, U. Narendrakumar, and I. Manjubala, "Commercial hydrogels for biomedical applications," Heliyon, vol. 6, no. 4, p. e03719, Apr. 2020, doi: 10.1016/j.heliyon.2020.e03719.

[78] S. J. Kim, S. S. Kwon, S. H. Jeon, E. R. Yu, and S. N. Park, "Enhanced skin delivery of liquiritigenin and liquiritin-loaded liposome-in-hydrogel complex system," pp. 553-560, 2014, doi: $10.1111 /$ ics.12156.

[79] F. Ullah, M. B. H. Othman, F. Javed, Z. Ahmad, and H. M. Akil, "Classification, processing and application of hydrogels: A review," Mater. Sci. Eng. C, vol. 57, pp. 414-433, 2015, doi: 10.1016/j.msec.2015.07.053.

[80] L. Li et al., "Natural hydrogels for cartilage regeneration: Modification, preparation and application," J. Orthop. Transl., vol. 17, no. 2, pp. 26-41, Apr. 2019, doi: 10.1016/j.jot.2018.09.003.

[81] W. Zhao, X. Jin, Y. Cong, Y. Liu, and J. Fu, "Degradable natural polymer hydrogels for articular cartilage tissue engineering," J. Chem. Technol. Biotechnol., vol. 88, no. 3, pp. 327-339, 2013, doi: $10.1002 /$ jctb.3970.

[82] H. T. Ta, C. R. Dass, and D. E. Dunstan, "Injectable chitosan hydrogels for localised cancer therapy," J. Control. Release, vol. 126, no. 3, pp. 205-216, Mar. 2008, doi: 10.1016/j.jconrel.2007.11.018.

[83] J. Liu, J. Li, F. Yu, Y. xin Zhao, X. mei Mo, and J. feng Pan, "In situ forming hydrogel of natural polysaccharides through Schiff base reaction for soft tissue adhesive and hemostasis," Int. J. Biol. Macromol., vol. 147, pp. 653-666, 2020, doi: 10.1016/j.ijbiomac.2020.01.005.

[84] I. Gholamali, "Stimuli-Responsive Polysaccharide Hydrogels for Biomedical Applications: a Review," Regen. Eng. Transl. Med., 2019, doi: 10.1007/s40883-019-00134-1.

[85] V. Gun'ko, I. Savina, and S. Mikhalovsky, "Properties of Water Bound in Hydrogels," Gels, vol. 3, no. 4, p. 37, 2017, doi: 10.3390/gels3040037.

[86] S. H. Park et al., "An injectable, click-crosslinked, cytomodulin-modified hyaluronic acid hydrogel for cartilage tissue engineering," NPG Asia Mater., vol. 11, no. 1, pp. 1-16, 2019, doi: 


\subsection{8/s41427-019-0130-1.}

[87] W. He, M. Reaume, M. Hennenfent, B. P. Lee, and R. Rajachar, "Biomimetic hydrogels with spatial- and temporal-controlled chemical cues for tissue engineering," Biomater. Sci., vol. 8, no. 12 , pp. 3248-3269, 2020, doi: 10.1039/d0bm00263a.

[88] J. Lee, M. N. Silberstein, A. A. Abdeen, S. Y. Kim, and K. A. Kilian, "Mechanochemical functionalization of disulfide linked hydrogels," Mater. Horizons, vol. 3, no. 5, pp. 447-451, 2016, doi: 10.1039/c6mh00091f.

[89] H. Tan and K. G. Marra, "Injectable, Biodegradable Hydrogels for Tissue Engineering Applications," Materials (Basel)., vol. 3, no. 3, pp. 1746-1767, Mar. 2010, doi: 10.3390/ma3031746.

[90] B. van Bochove and D. W. Grijpma, "Photo-crosslinked synthetic biodegradable polymer networks for biomedical applications," J. Biomater. Sci. Polym. Ed., vol. 30, no. 2, pp. 77-106, Jan. 2019, doi: 10.1080/09205063.2018.1553105.

[91] E. Zant and D. W. Grijpma, "Synthetic Biodegradable Hydrogels with Excellent Mechanical Properties and Good Cell Adhesion Characteristics Obtained by the Combinatorial Synthesis of Photo-Cross-Linked Networks," Biomacromolecules, vol. 17, no. 5, pp. 1582-1592, 2016, doi: 10.1021/acs.biomac.5b01721.

[92] A. Islam et al., "Evaluation of selected properties of biocompatible chitosan/poly(vinyl alcohol) blends," Int. J. Biol. Macromol., vol. 82, no. October, pp. 551-556, 2016, doi: 10.1016/j.ijbiomac.2015.09.073.

[93] D. Hu et al., "Ultrahigh strength nanocomposite hydrogels designed by locking oriented tunicate cellulose nanocrystals in polymeric networks," Compos. Part B Eng., vol. 197, no. May, p. 108118, 2020, doi: 10.1016/j.compositesb.2020.108118.

[94] L. Zhu, J. Qiu, and E. Sakai, "A high modulus hydrogel obtained from hydrogen bond reconstruction and its application in vibration damper," RSC Adv., vol. 7, no. 69, pp. 4375543763, 2017, doi: 10.1039/c7ra08272j.

[95] L. Zhu et al., "Design of a Rubbery Carboxymethyl Cellulose/Polyacrylic Acid Hydrogel via Visible-Light-Triggered Polymerization," Macromol. Mater. Eng., vol. 302, no. 6, pp. 1-9, 2017, doi: 10.1002/mame.201600509.

[96] M. A. Przeradzka, B. van Bochove, T. C. Bor, and D. W. Grijpma, "Phase-separated mixedmacromer hydrogel networks and scaffolds prepared by stereolithography," Polym. Adv. Technol., vol. 28, no. 10, pp. 1212-1218, 2017, doi: 10.1002/pat.3916.

[97] D. Wirthl, R. Pichler, M. Drack, G. Kettlguber, R. Moser, R. Gerstmayr et al., "Instant tough bonding of hydorgels for soft machines and electronics" Science Advances, Vol. 3, no. 6, 2017, doi: 10.1126/sciadv.1700053

[98] Yuk, H. et al. Skin-inspired hydrogel-elastomer hybrids with robust interfaces and functional microstructures. Nat. Commun. 7:12028 doi: 10.1038/ncomms12028 (2016)

[99] M. A. North, C. A. Del Grosso, and J. J. Wilker, "High Strength Underwater Bonding with Polymer Mimics of Mussel Adhesive Proteins," ACS Appl. Mater. Interfaces, vol. 9, no. 8, pp. 7866-7872, 2017, doi: 10.1021/acsami.7b00270.

[100] J. Nishida, Y. Higaki, and A. Takahara, "Synthesis and characterization of barnacle adhesive mimetic towards underwater adhesion," Chem. Lett., vol. 44, no. 8, pp. 1047-1049, 2015, doi: 10.1246/cl.150311. 
[101] P. Glass, H. Chung, N. R. Washburn, and M. Sitti, "Enhanced reversible adhesion of dopamine methacrylamide-coated elastomer microfibrillar structures under wet conditions," Langmuir, vol. 25, no. 12, pp. 6607-6612, 2009, doi: 10.1021/la9009114.

[102] C. R. So et al., "Sequence basis of Barnacle Cement Nanostructure is Defined by Proteins with Silk Homology," Sci. Rep., vol. 6, pp. 1-14, 2016, doi: 10.1038/srep36219.

[103] "Polyphenolic Substance of Mytilus edulis : Novel Adhesive Containing L-Dopa and Hydroxyproline: J . Herbert Waite and Marvin L. Tanzer Published by : American Association for the Advancement of Science Stable," vol. 212, no. 4498, pp. 1038-1040, 2017.

[104] Marie Krogsgaard, Vicki Nue, and Henrik Birkedal, Mussel-Inspired Materials: Self-Healing through Coordination Chemistry, Chem. Eur. J. 2016, 22, pp. 844 857,doi:10.1002/chem.201503380

[105] A. Mahdavi et al., A biodegradable and biocompatible gecko-inspired tissue adhesive, National Academy of Sciences 2008, doi: 10.1073/pnas.0712117105.

[106] H. Lee, B. P. Lee and P. B. Messersmith, A reversible wet/dry adhesive inspired by mussels and geckos, Nature, Vol 448, 2007, doi: 10.1038/nature05968.

[107] J. Li, Y. Liu, J. Luo, P. Liu, and C. Zhang, "Excellent lubricating behavior of Brasenia schreberi mucilage," Langmuir, vol. 28, no. 20, pp. 7797-7802, 2012, doi: 10.1021/la300957v.

[108] P. Liu, Y. Liu, Y. Yang, Z. Chen, J. Li, and J. Luo, "Mechanism of biological liquid superlubricity of brasenia schreberi mucilage," Langmuir, vol. 30, no. 13, pp. 3811-3816, 2014, doi: 10.1021/la500193n.

[109] N. J. Irwin, M. G. Bryant, C. P. McCoy, J. L. Trotter, and J. Turner, "Multifunctional, Low Friction, Antimicrobial Approach for Biomaterial Surface Enhancement," ACS Appl. Bio Mater., vol. 3, no. 3, pp. 1385-1393, 2020, doi: 10.1021/acsabm.9b01042.

[110] N. J. A. Chan et al., "Spider-silk inspired polymeric networks by harnessing the mechanical potential of $\beta$-sheets through network guided assembly," Nat. Commun., vol. 11, no. 1, pp. 114, 2020, doi: 10.1038/s41467-020-15312-x.

[111] T. T. Hoang Thi, Y. Lee, P. Le Thi, and K. D. Park, "Engineered horseradish peroxidase-catalyzed hydrogels with high tissue adhesiveness for biomedical applications," J. Ind. Eng. Chem., vol. 78, pp. 34-52, 2019, doi: 10.1016/j.jiec.2019.05.026.

[112] T. B. Reece, T. S. Maxey, and I. L. Kron, "A prospectus on tissue adhesives," Am. J. Surg., vol. 182, no. 2 SUPPL. 1, pp. S40-S44, 2001, doi: 10.1016/S0002-9610(01)00742-5.

[113] F. Scognamiglio et al., "Adhesive and sealant interfaces for general surgery applications," J. Biomed. Mater. Res. - Part B Appl. Biomater., vol. 104, no. 3, pp. 626-639, 2016, doi: 10.1002/jbm.b.33409.

[114] M. Mehdizadeh and J. Yang, "Design Strategies and Applications of Tissue Bioadhesives," Macromol. Biosci., vol. 13, no. 3, pp. 271-288, 2013, doi: 10.1002/mabi.201200332.

[115] P. J. M. Bouten et al., "The chemistry of tissue adhesive materials," Prog. Polym. Sci., vol. 39, no. 7, pp. 1375-1405, 2014, doi: 10.1016/j.progpolymsci.2014.02.001.

[116] K. Tian, J. Bae, Z. Suo, and J. J. Vlassak, "Adhesion between Hydrophobic Elastomer and Hydrogel through Hydrophilic Modification and Interfacial Segregation," ACS Appl. Mater. 
Interfaces, vol. 10, no. 49, pp. 43252-43261, 2018, doi: 10.1021/acsami.8b16445.

[117] J. Yang, R. Bai, B. Chen, and Z. Suo, "Hydrogel Adhesion: A Supramolecular Synergy of Chemistry, Topology, and Mechanics," Adv. Funct. Mater., vol. 30, no. 2, pp. 1-27, 2020, doi: 10.1002/adfm.201901693.

[118] H. Yang et al., "Printing Hydrogels and Elastomers in Arbitrary Sequence with Strong Adhesion," Adv. Funct. Mater., vol. 29, no. 27, pp. 1-8, 2019, doi: 10.1002/adfm.201901721.

[119] H. G. Silverman and F. F. Roberto, "Understanding marine mussel adhesion," Mar. Biotechnol., vol. 9, no. 6, pp. 661-681, 2007, doi: 10.1007/s10126-007-9053-x.

[120] J. H. WAITE, “Adhesion a la Moule," Biochemistry, vol. 1180, pp. 1172-1180, 2002.

[121] H. Lee, N. F. Scherer, and P. B. Messersmith, "Single-molecule mechanics of mussel adhesion," Proc. Natl. Acad. Sci. U. S. A., vol. 103, no. 35, pp. 12999-13003, 2006, doi: 10.1073/pnas.0605552103.

[122] N. Ye, J. L. Neumeyer, R. J. Baldessarini, X. Zhen, and A. Zhang, "Update 1 of: Recent progress in development of dopamine receptor subtype-selective agents: Potential therapeutics for neurological and psychiatric disorders," Chem. Rev., vol. 113, no. 5, pp. 274-302, 2013, doi: 10.1021/cr300113a.

[123] Q. Ye, F. Zhou, and W. Liu, "Bioinspired catecholic chemistry for surface modification," Chem. Soc. Rev., vol. 40, no. 7, pp. 4244-4258, 2011, doi: 10.1039/c1cs15026j.

[124] M. Krogsgaard, V. Nue, and H. Birkedal, "Mussel-Inspired Materials: Self-Healing through Coordination Chemistry," Chem. - A Eur. J., vol. 22, no. 3, pp. 844-857, 2016, doi: 10.1002/chem.201503380.

[125] M. Puertas-Bartolomé, B. Vázquez-Lasa, J. San Román Bioactive and Bioadhesive Catechol Conjugated Polymers for Tissue Regeneration, Polymers, 2018

[126] J. Su,F. Chen, V. L. Cryns, P.B. Messersmith, Catechol Polymers for pH-Responsive, Targeted Drug Delivery to Cancer Cells, J. Am. Chem. Soc. 2011, 133, 11850-11853

[127] Y. Zhang et al., "A Bioadhesive Nanoparticle-Hydrogel Hybrid System for Localized Antimicrobial Drug Delivery," ACS Appl. Mater. Interfaces, vol. 8, no. 28, pp. 18367-18374, 2016, doi: 10.1021/acsami.6b04858.

[128] M. Patenaude, N. M. B. Smeets, and T. Hoare, "Designing Injectable, Covalently Cross-Linked Hydrogels for Biomedical Applications," no. 35, pp. 598-617, 2014.

[129] A. Sivashanmugam, R. Arun Kumar, M. Vishnu Priya, S. V Nair, and R. Jayakumar, "An overview of injectable polymeric hydrogels for tissue engineering," Eur. Polym. J., vol. 72, pp. 543-565, Nov. 2015, doi: 10.1016/j.eurpolymj.2015.05.014.

[130] Y. Xu et al., "Injectable photo-crosslinking cartilage decellularized extracellular matrix for cartilage tissue regeneration," Mater. Lett., vol. 268, p. 127609, Jun. 2020, doi: 10.1016/j.matlet.2020.127609.

[131] C. Li, Z. Huang, N. Gao, J. Zheng, and J. Guan, "Injectable, thermosensitive, fast gelation, bioeliminable, and oxygen sensitive hydrogels," Mater. Sci. Eng. C, vol. 99, no. December 2018, pp. 1191-1198, 2019, doi: 10.1016/j.msec.2019.02.075.

[132] T. N. Vo et al., "Injectable dual-gelling cell-laden composite hydrogels for bone tissue 
engineering," Biomaterials, vol. 83, pp. 1-11, Mar. 2016, doi: 10.1016/j.biomaterials.2015.12.026.

[133] R. Dimatteo, N. J. Darling, and T. Segura, "In situ forming injectable hydrogels for drug delivery and wound repair," Adv. Drug Deliv. Rev., vol. 127, pp. 167-184, Mar. 2018, doi: 10.1016/j.addr.2018.03.007.

[134] L. Yuan, Y. Wu, Q. sheng Gu, H. El-Hamshary, M. El-Newehy, and X. Mo, "Injectable photo crosslinked enhanced double-network hydrogels from modified sodium alginate and gelatin," Int. J. Biol. Macromol., vol. 96, pp. 569-577, Mar. 2017, doi: 10.1016/j.ijbiomac.2016.12.058.

[135] Q. Xu et al., "A hybrid injectable hydrogel from hyperbranched PEG macromer as a stem cell delivery and retention platform for diabetic wound healing," Acta Biomater., vol. 75, pp. 6374, 2018, doi: 10.1016/j.actbio.2018.05.039.

[136] Zair, L., Skrobot, J., Marchlewicz, M., Lichota, J., Gugała, L., Kuczynska, M., Zeair, S., Duchnik, E., Tejchman, K., Wiszniewska, B., Sienko, J., Sulikowski, T., Ostrowski, M., El Fray, $M$. Abdominal hernia repair surgery with the new injectable polymer biomaterials (2015) New Medicine, 19 (2), pp. 43-50.

[137] J. Skrobot, L. Zair, M. Ostrowski, M. El Fray, New injectable elastomeric biomaterials for hernia repair and their biocompatibility, Biomaterials, vol. 75, 2016, pp.182-192

[138] B. D. Ulery, L. S. Nair, and C. T. Laurencin, "Biomedical applications of biodegradable polymers," J. Polym. Sci. Part B Polym. Phys., vol. 49, no. 12, pp. 832-864, 2011, doi: 10.1002/polb.22259.

[139] L. S. Nair and C. T. Laurencin, "Biodegradable polymers as biomaterials," Prog. Polym. Sci., vol. 32, no. 8-9, pp. 762-798, 2007, doi: 10.1016/j.progpolymsci.2007.05.017.

[140] Q. Liu, L. Jiang, R. Shi, and L. Zhang, "Synthesis, preparation, in vitro degradation, and application of novel degradable bioelastomers - A review," Prog. Polym. Sci., vol. 37, no. 5, pp. 715-765, 2012, doi: 10.1016/j.progpolymsci.2011.11.001.

[141] M. Gigli, M. Fabbri, N. Lotti, R. Gamberini, B. Rimini, and A. Munari, "Poly(butylene succinate)based polyesters for biomedical applications: A review," Eur. Polym. J., vol. 75, pp. 431-460, 2016, doi: 10.1016/j.eurpolymj.2016.01.016.

[142] Helena S. Azevedo and Rui L. Reis, Understanding the Enzymatic Degradation of Biodegradable Polymers and Strategies to Control Their Degradation Rate, Biodegradable Systems in Tissue Engineering and Regenerative Medicine, Chapter 12

[143] J. Skrobot, W. Ignaczak, M. El Fray, "Hydrolytic and enzymatic degradation of flexible polymer networks comprising fatty acid derivatives", Polymer Degradation and Stability 120 (2015) 368e376, http://dx.doi.org/10.1016/j.polymdegradstab.2015.07.022

[144] A. Banerjee, K. Chatterjee, and G. Madras, "Enzymatic degradation of polymers: a brief review", Materials Science and Technology, 567-573,2014, DOI:10.1179/1743284713Y.0000000503

[145] J. P. Santerre,R . S. Labow,, D. G. Duguay Erfle, and G. A. Adams, "Biodegradation evaluation of polyether and polyester-urethanes with oxidative and hydrolytic enzymes", Journal of Biomedical Materials Research, Vol. 28, 1187-1199 (1994), doi: $10.1002 / \mathrm{jbm} .820281009$.

[146] A. Eskandarinia et al., "A Novel Bilayer Wound Dressing Composed of a Dense 
Polyurethane/Propolis Membrane and a Biodegradable Polycaprolactone/Gelatin Nanofibrous Scaffold," Sci. Rep., vol. 10, no. 1, pp. 1-15, 2020, doi: 10.1038/s41598-02059931-2.

[147] K. R. Remya, S. Chandran, S. Mani, A. John, and P. Ramesh, "Hybrid polycaprolactone/polyethylene oxide scaffolds with tunable fiber surface morphology, improved hydrophilicity and biodegradability for bone tissue engineering applications," J. Biomater. Sci. Polym. Ed., vol. 29, no. 12, pp. 1444-1462, 2018, doi: 10.1080/09205063.2018.1465664.

[148] N. A. Peppas, J. Z. Hilt, A. Khademhosseini, and R. Langer, "Hydrogels in biology and medicine: From molecular principles to bionanotechnology," Adv. Mater., vol. 18, no. 11, pp. 13451360, 2006, doi: 10.1002/adma.200501612.

[149] J. W. Nichol and A. Khademhosseini, "Modular tissue engineering: Engineering biological tissues from the bottom up," Soft Matter, vol. 5, no. 7, pp. 1312-1319, 2009, doi: 10.1039/b814285h.

[150] B. B. Mandal and S. C. Kundu, "Cell proliferation and migration in silk fibroin 3D scaffolds," Biomaterials, vol. 30, no. 15, pp. 2956-2965, 2009, doi: 10.1016/j.biomaterials.2009.02.006.

[151] S. M. Lien, L. Y. Ko, and T. J. Huang, "Effect of pore size on ECM secretion and cell growth in gelatin scaffold for articular cartilage tissue engineering," Acta Biomater., vol. 5, no. 2, pp. 670-679, 2009, doi: 10.1016/j.actbio.2008.09.020.

[152] D. J. Griffon, M. R. Sedighi, D. V. Schaeffer, J. A. Eurell, and A. L. Johnson, "Chitosan scaffolds: Interconnective pore size and cartilage engineering," Acta Biomater., vol. 2, no. 3, pp. 313320, 2006, doi: 10.1016/j.actbio.2005.12.007.

[153] H. J. Kim, U. J. Kim, G. Vunjak-Novakovic, B. H. Min, and D. L. Kaplan, "Influence of macroporous protein scaffolds on bone tissue engineering from bone marrow stem cells," Biomaterials, vol. 26, no. 21, pp. 4442-4452, 2005, doi: 10.1016/j.biomaterials.2004.11.013.

[154] T. Dutta Roy, J. L. Simon, J. L. Ricci, E. D. Rekow, V. P. Thompson, and J. R. Parsons, "Performance of degradable composite bone repair products made via three-dimensional fabrication techniques," J. Biomed. Mater. Res. - Part A, vol. 66, no. 2, pp. 283-291, 2003, doi: 10.1002/jbm.a.10582.

[155] K. Kanimozhi, S. K. Basha, V. S. Kumari, and K. Kaviyarasu, "Development of Biomimetic Hybrid Porous Scaffold of Chitosan/Polyvinyl Alcohol/Carboxymethyl Cellulose by Freeze-Dried and Salt Leached Technique," J. Nanosci. Nanotechnol., vol. 18, no. 7, pp. 4916-4922, 2017, doi: 10.1166/jnn.2018.15306.

[156] V. B. Morris, S. Nimbalkar, M. Younesi, P. McClellan, and O. Akkus, "Mechanical Properties, Cytocompatibility and Manufacturability of Chitosan:PEGDA Hybrid-Gel Scaffolds by Stereolithography," Ann. Biomed. Eng., vol. 45, no. 1, pp. 286-296, 2017, doi: 10.1007/s10439-016-1643-1.

[157] S. Piarali et al., "Activated Polyhydroxyalkanoate Meshes Prevent Bacterial Adhesion and Biofilm Development in Regenerative Medicine Applications," Front. Bioeng. Biotechnol., vol. 8, no. May, pp. 1-14, 2020, doi: 10.3389/fbioe.2020.00442.

[158] K. M. Muzammil et al., "Castor oil reinforced polymer hybrids for skin tissue augmentation," Int. J. Polym. Mater. Polym. Biomater., vol. 0, no. 0, pp. 1-15, 2020, doi: 10.1080/00914037.2020.1740986.

[159] L. N. M. Ribeiro et al., "Advances in Hybrid Polymer-Based Materials for Sustained Drug 
Release," Int. J. Polym. Sci., vol. 2017, 2017, doi: 10.1155/2017/1231464.

[160] M. Mohammadi, S. Taghavi, K. Abnous, S. M. Taghdisi, M. Ramezani, and M. Alibolandi, "Hybrid Vesicular Drug Delivery Systems for Cancer Therapeutics," Adv. Funct. Mater., vol. 28, no. 36, pp. 1-18, 2018, doi: 10.1002/adfm.201802136.

[161] D. C. Ferreira Soares, S. C. Domingues, D. B. Viana, and M. L. Tebaldi, "Polymer-hybrid nanoparticles: Current advances in biomedical applications," Biomed. Pharmacother., vol. 131, no. September, p. 110695, 2020, doi: 10.1016/j.biopha.2020.110695.

[162] S. Maghrebi, C. A. Prestidge, and P. Joyce, "An update on polymer-lipid hybrid systems for improving oral drug delivery," Expert Opin. Drug Deliv., vol. 16, no. 5, pp. 507-524, 2019, doi: 10.1080/17425247.2019.1605353.

[163] D. Pandita, S. Kumar, V. Lather Hybrid poly(lactic-co-glycolic acid) nanoparticles: design and delivery prospectives,2015, Drug Discovery Today, vol. 20, $\mathrm{nr}$ 1, http://dx.doi.org/10.1016/j.drudis.2014.09.018

[164] S. Allison et al., "Electroconductive nanoengineered biomimetic hybrid fibers for cardiac tissue engineering," J. Mater. Chem. B, vol. 5, no. 13, pp. 2402-2406, 2017, doi: 10.1039/С7TB00405B.

[165] M. Setayeshmehr et al., "Hybrid and composite scaffolds based on extracellular matrices for cartilage tissue engineering," Tissue Eng. - Part B Rev., vol. 25, no. 3, pp. 202-224, 2019, doi: 10.1089/ten.teb.2018.0245.

[166] V. C. Costa, H. S. Costa, W. L. Vasconcelos, M. de M. Pereira, R. L. Oréfice, and H. S. Mansur, "Preparation of hybrid biomaterials for bone tissue engineering," Mater. Res., vol. 10, no. 1, pp. 21-26, 2007, doi: 10.1590/S1516-14392007000100006.

[167] S. C. Neves, L. Moroni, C. C. Barrias, and P. L. Granja, "Leveling Up Hydrogels: Hybrid Systems in Tissue Engineering," Trends Biotechnol., vol. 38, no. 3, pp. 292-315, 2020, doi: 10.1016/j.tibtech.2019.09.004.

[168] O. Yousefzade, R. Katsarava, and J. Puiggalí, "Biomimetic Hybrid Systems for Tissue Engineering," Biomimetics, vol. 5, no. 4, p. 49, 2020, doi: 10.3390/biomimetics5040049. 